\title{
Uncertainty of wheat water use: Simulated patterns and sensitivity to temperature and $\mathrm{CO}_{2}$
}

\author{
Davide Cammarano $^{\mathrm{a}, *}$, Reimund P. Rötter ${ }^{\mathrm{b}, \mathrm{O}}$, Senthold Asseng ${ }^{\mathrm{a}}$, Frank Ewert ${ }^{\mathrm{c}, \mathrm{P}}$, \\ Daniel Wallach $^{\mathrm{d}}$, Pierre Martre ${ }^{\mathrm{e}, \mathrm{f}, 1}$, Jerry L. Hatfield ${ }^{\mathrm{g}}$, James W. Jones ${ }^{\mathrm{a}}$, \\ Cynthia Rosenzweig ${ }^{h}$, Alex C. Ruane ${ }^{h}$, Kenneth J. Boote ${ }^{a}$, Peter J. Thorburn ${ }^{\mathrm{i}}$,
} Kurt Christian Kersebaum ${ }^{j}$, Pramod K. Aggarwal ${ }^{k}$, Carlos Angulo $^{c}$, Bruno Basso ${ }^{1}$, Patrick Bertuzzi ${ }^{\mathrm{m}}$, Christian Biernath ${ }^{\mathrm{n}}$, Nadine Brisson ${ }^{\mathrm{o}, \mathrm{p}, 3}{ }^{3}$, Andrew J. Challinor ${ }^{\mathrm{q}, \mathrm{r}}$, Jordi Doltra ${ }^{\mathrm{s}}$, Sebastian Gayler ${ }^{\mathrm{t}}$, Richie Goldberg ${ }^{\mathrm{h}}$, Lee Heng ${ }^{\mathrm{u}}$, Josh Hooker ${ }^{\mathrm{v}, \mathrm{w}}$, Leslie A. Hunt ${ }^{\mathrm{x}}$, Joachim Ingwersen ${ }^{\mathrm{y}}$, Roberto C. Izaurralde ${ }^{\mathrm{z}, \mathrm{A}}$, Christoph Müller ${ }^{\mathrm{B}}$, Soora Naresh Kumar $^{C}$, Claas Nendel ${ }^{\mathrm{j}}$, Garry J. O'Leary ${ }^{\mathrm{D}}$, Jørgen E. Olesen ${ }^{\mathrm{E}}$, Tom M. Osborne ${ }^{\mathrm{F}}$, Taru Palosuo ${ }^{\mathrm{b}}$, Eckart Priesack ${ }^{\mathrm{n}}$, Dominique Ripoche ${ }^{\mathrm{m}}$, Mikhail A. Semenov ${ }^{G}$, Iurii Shcherbak ${ }^{1}$, Pasquale Steduto ${ }^{\mathrm{H}}$, Claudio O. Stöckle ${ }^{\mathrm{I}}$, Pierre Stratonovitch ${ }^{G}$, Thilo Streck ${ }^{\mathrm{y}}$, Iwan Supit ${ }^{\mathrm{J}}$, Fulu Tao ${ }^{\mathrm{b}, \mathrm{K}}{ }^{\text {, Maria }}$ Travasso $^{\mathrm{L}}$, Katharina Waha ${ }^{\mathrm{B}, 2}$, Jeffrey W. White ${ }^{\mathrm{M}}$, Joost Wolf ${ }^{\mathrm{N}}$

a Agricultural \& Biological Engineering Department, University of Florida, Gainesville, FL 32611, United States

${ }^{\mathrm{b}}$ Natural Resources Institute Finland (Luke), FI-00790 Helsinki, Finland

${ }^{\mathrm{c}}$ Institute of Crop Science and Resource Conservation (INRES), Universität Bonn, 53115, Germany

d National Institute for Agricultural Research (INRA), UMR1248 Agrosystèmes et développement territorial, 31326 Castanet-Tolosan Cedex, France

e INRA, UMR1095 Genetics, Diversity and Ecophysiology of Cereals (GDEC), F-63 100 Clermont-Ferrand, France

${ }^{\mathrm{f}}$ Blaise Pascal University, UMR1095 GDEC, F-63 170 Aubière, France

g National Laboratory for Agriculture and Environment, Ames, IA 50011, United States

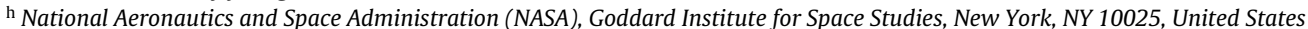

${ }^{i}$ Commonwealth Scientific and Industrial Research Organization (CSIRO), Ecosystem Sciences, Dutton Park QLD 4102, Australia

j Institute of Landscape Systems Analysis, Leibniz Centre for Agricultural Landscape Research, 15374 Müncheberg, Germany

${ }^{\mathrm{k}}$ CGIAR Research Program on Climate Change, Agriculture and Food Security, CIMMYT, New Delhi 110012, India

${ }^{1}$ Department of Geological Sciences and Kellogg Biological Station, Michigan State University, East Lansing, MI, United States

m National Institute for Agricultural Research (INRA), US1116 AgroClim, F- 84914 Avignon, France

${ }^{\mathrm{n}}$ Institute of Soil Ecology, Helmholtz Zentrum München, German Research Center for Environmental Health, Neuherberg, D-85764, Germany

${ }^{\circ}$ National Institute for Agricultural Research (INRA), UMR0211 Agronomie, F-78750 Thiverval-Grignon, France

p AgroParisTech, UMR0211 Agronomie, F-78750 Thiverval-Grignon, France

${ }^{\mathrm{q}}$ Institute for Climate and Atmospheric Science, School of Earth and Environment, University of Leeds, Leeds LS29JT, United Kingdom

${ }^{r}$ CGIAR-ESSP Program on Climate Change, Agriculture and Food Security, International Centre for Tropical Agriculture (CIAT), A.A. 6713, Cali, Colombia

${ }^{s}$ Cantabrian Agricultural Research and Training Centre (CIFA), 39600 Muriedas, Spain

${ }^{\mathrm{t}}$ Water E' Earth System Science Competence Cluster, c/o University of Tübingen, 72074 Tübingen, Germany

u International Atomic Energy Agency, 1400 Vienna, Austria

v School of Agriculture, Policy and Development, University of Reading, RG6 6AR, United Kingdom

w Joint Research Center, via Enrico Fermi, 2749 Ispra, 21027 Italy

x Department of Plant Agriculture, University of Guelph, Guelph, Ontario, N1G 2W1, Canada

${ }^{y}$ Institute of Soil Science and Land Evaluation, Universität Hohenheim, 70599 Stuttgart, Germany

${ }^{z}$ Dept. of Geographical Sciences, Univ. of Maryland, College Park, MD 20742, United States

A Texas AEM AgriLife Research and Extension Center, Texas AEM Univ., Temple, TX 76502, United States

B Potsdam Institute for Climate Impact Research, 14473 Potsdam, Germany

C Centre for Environment Science and Climate Resilient Agriculture, Indian Agricultural Research Institute, New Delhi 110012 , India

${ }^{D}$ Landscape E Water Sciences, Department of Economic Development, Jobs, Transport and Resources, Horsham, Victoria 3400, Australia

E Department of Agroecology, Aarhus University, 8830, Tjele, Denmark

F National Centre for Atmospheric Science, Department of Meteorology, University of Reading, RG6 6BB, United Kingdom

\footnotetext{
* Corresponding author. Present Address: The James Hutton Institute, Invergowrie, Dundee, DD2 5DA, U.K.

E-mail addresses: Davide.Cammarano@hutton.ac.uk, davide.cammarano@ufl.edu, davide.cammarano@gmail.com (D. Cammarano).

1 Present address: INRA, Montpellier SupAgro, UMR759 Laboratoire d'Ecophysiologie des Plantes sous Stress Environnementaux, F-34 060 Montpellier, France.

2 Present address: Commonwealth Scientific and Industrial Research Organization (CSIRO), Agriculture, 306 Carmody Road, 4067 St.Lucia, Australia.

3 Passed away in 2011 while this work was being carried out.
} 
G Computational and Systems Biology Department, Rothamsted Research, Harpenden, Herts, AL5 2JQ United Kingdom

${ }^{\mathrm{H}}$ Food and Agriculture Organization of the United Nations (FAO), Rome, Italy

I Biological Systems Engineering, Washington State University, Pullman, WA 99164-6120, United States

J Water Sytems and Global Change Group, Wageningen University, The Netherlands

${ }^{\mathrm{K}}$ Institute of Geographical Sciences and Natural Resources Research, Chinese Academy of Science, Beijing 100101, China

${ }^{\mathrm{L}}$ Institute for Climate and Water, INTA-CIRN, 1712 Castelar, Argentina

${ }^{\mathrm{M}}$ USDA ARS, ALARC, Maricopa, AZ, USA

$\mathrm{N}$ Plant Production Systems, Wageningen University, 6700AA Wageningen 37, The Netherlands

${ }^{\circ}$ Department of Crop Sciences, Georg-August-University Goettingen, Germany

${ }^{\mathrm{P}}$ Leibniz Centre for Agricultural Landscape Research (ZALF), 15374 Müncheberg, Germany

\section{A R T I C L E I N F O}

Article history:

Received 19 February 2016

Received in revised form 16 June 2016

Accepted 10 August 2016

Available online 31 August 2016

\section{Keywords:}

Multi-model simulation

Transpiration efficiency

Water use

Uncertainty

Sensitivity

\begin{abstract}
A B S T R A C T
Projected global warming and population growth will reduce future water availability for agriculture. Thus, it is essential to increase the efficiency in using water to ensure crop productivity. Quantifying crop water use (WU; i.e. actual evapotranspiration) is a critical step towards this goal. Here, sixteen wheat simulation models were used to quantify sources of model uncertainty and to estimate the relative changes and variability between models for simulated WU, water use efficiency (WUE, WU per unit of grain dry mass produced), transpiration efficiency ( $T_{\text {eff }}$, transpiration per $\mathrm{kg}$ of unit of grain yield dry mass produced), grain yield, crop transpiration and soil evaporation at increased temperatures and elevated atmospheric carbon dioxide concentrations $\left(\left[\mathrm{CO}_{2}\right]\right)$. The greatest uncertainty in simulating water use, potential evapotranspiration, crop transpiration and soil evaporation was due to differences in how crop transpiration was modelled and accounted for $50 \%$ of the total variability among models. The simulation results for the sensitivity to temperature indicated that crop WU will decline with increasing temperature due to reduced growing seasons. The uncertainties in simulated crop WU, and in particularly due to uncertainties in simulating crop transpiration, were greater under conditions of increased temperatures and with high temperatures in combination with elevated atmospheric $\left[\mathrm{CO}_{2}\right]$ concentrations. Hence the simulation of crop WU, and in particularly crop transpiration under higher temperature, needs to be improved and evaluated with field measurements before models can be used to simulate climate change impacts on future crop water demand.
\end{abstract}

(C) 2016 Elsevier B.V. All rights reserved.

\section{Introduction}

Globally, agriculture uses about $70 \%$ of all freshwater withdrawals for irrigation, although discrepancies exist in the quantified amount (Alcamo et al., 2007; Howell, 2001; Shen et al., 2008). About $70 \%$ of the world's wheat production comes from irrigated or high rainfall regions, with the majority of irrigation concentrated in developing countries with high population density, particularly large producers like China and India (Dixon et al., 2009; Reynolds and Braun, 2013). Projections that global food demand will double by 2050 highlight the challenges agriculture is facing with the need to produce more food with less land and less water (Foley et al., 2011; Godfray et al., 2010). Due to continued population growth, urbanization and industrialization, agriculture will increasingly compete with other sectors for freshwater (Godfray et al., 2010; Siebert and Doll, 2010; Tilman et al., 2011), and climate change may further limit water availability for irrigation in many cropping areas (Elliott et al., 2014). In rainfed agricultural environments, where crops rely on rainfall alone, future changes in rainfall patterns, temperature conditions, and increases in atmospheric carbon dioxide concentrations $\left(\left[\mathrm{CO}_{2}\right]\right)$ will affect crop production (Challinor et al., 2014; Knox et al., 2012; Müller and Robertson, 2014; Rosenzweig and Parry, 1994; Rötter and Van de Geijn, 1999).

Passioura (2006) discussed how the term "water productivity", in the context of agriculture, has different meanings to different people in terms of significance and timescale of interest. Similarly, different aspects of the water used in agriculture are of interest to different actors and stakeholders. These aspects are often characterized in terms of crop water use (WU, known also as actual evapotranspiration), water use efficiency (WUE, defined in Eq. (7)), and transpiration efficiency ( $\mathrm{T}_{\text {eff }}$, defined in Eq. (8)). For example, breeders use the ratio of agronomic performance (e.g. grain yield) to cumulated WU (WUE) as a basis for identifying crop ideotypes with better productivity, agronomists use WUE as a benchmark for identifying management practices suitable for irrigated or rainfed cultivation, while farmers may be more interested in WUE from an economic point of view (e.g. the monetary outcome such as marketable yield, given a unit of input used to produce it) (Blum, 2005; Condon et al., 2002; Passioura, 2006; Passioura and Angus, 2010; Sadras and Angus, 2006; Semenov et al., 2014). The improvement of crop productivity through management and breeding for high WUE has been the subject of numerous studies (Condon et al., 2004; Condon et al., 2002; Sinclair and Muchow, 2001). Tools that extrapolate the effects of future temperature and $\left[\mathrm{CO}_{2}\right]$ changes on how $\mathrm{WU}, \mathrm{WUE}$, and $\mathrm{T}_{\text {eff }}$ are likely to respond can complement information from field/greenhouse-based experiments for developing guidance on suitable climate change adaptations.

Crop simulation models (CSMs) are increasingly used to explore and assess climate change impacts on agriculture (Angulo et al., 2013; Osborne et al., 2013; White et al., 2011a). CSMs can account for multiple interactions among climate, crop, soil and management. CSMs differ in the way they simulate soil-plant-atmosphere processes and in the number of parameters and inputs required (Rötter et al., 2012; White et al., 2011a). Some CSMs have been developed, evaluated and applied in specific agro-environments, and these models don't perform equally well across all environments.

Single CSMs have usually been used to assess biophysical impacts due to climate change, but it is not possible to evaluate various sources of uncertainty with a single CSM (White et al., 

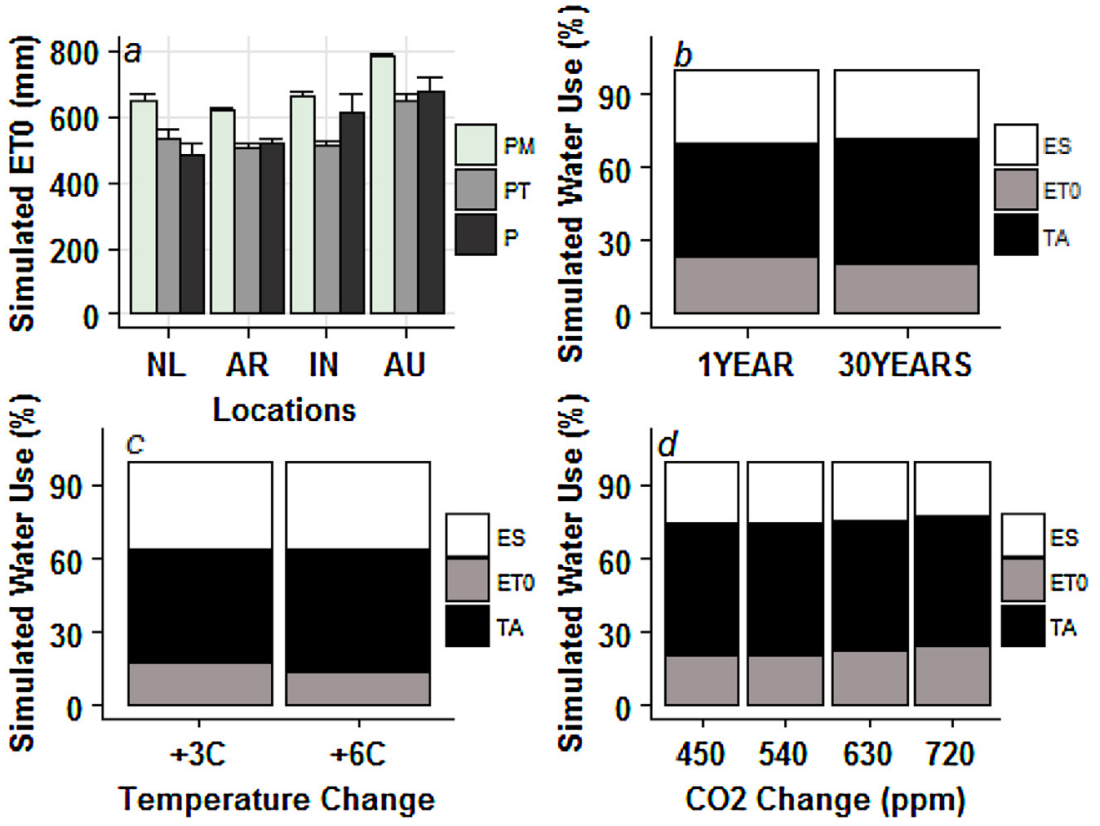

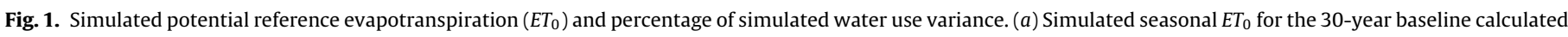

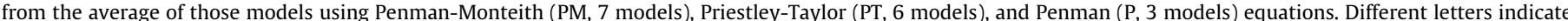

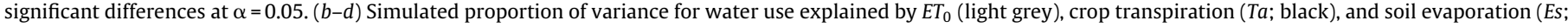
white) for $(b)$ the experimental year and the 30-year baseline, $(c)$ average daily air temperature increases, and $(d)$ increasing atmospheric $\mathrm{CO}_{2}$ concentrations.

2011a). One method of studying uncertainties in climate models that has become common practice is to use ensembles of multiple global and regional climate models (Mearns et al., 1997; Tebaldi and Knutti, 2007). Until recently, model ensembles have seen limited use in modelling climate change impact on agriculture (Rötter et al., 2011). Mean or median simulations from multi-model ensembles are usually more accurate than any individual model (Asseng et al., 2013; Martre et al., 2015; Rötter et al., 2012). A further benefit of ensembles is that the variability among the simulations from an ensemble can be used to estimate the uncertainty range when using different CSMs.

In this paper we used simulations from a recent multi-model study (Asseng et al., 2013) that focused solely on wheat grain yield, to explore simulations of crop WU, WUE, and $\mathrm{T}_{\text {eff }}$ and their variability and sensitivity to temperature and $\left[\mathrm{CO}_{2}\right]$ changes.

The objectives of this study were to: i) quantify the contributions of sources of model uncertainty to calculations of crop transpiration, soil evaporation, and potential evapotranspiration; and to ii) estimate the relative changes, the patterns and the variability between models for the simulated WU, WUE, $T_{\text {eff }}$, yield, crop transpiration and soil evaporation at elevated temperatures and $\left[\mathrm{CO}_{2}\right]$.

\section{Materials and methods}

\subsection{Experimental sites}

Experimental data from four locations with contrasting growing season rainfall and temperature were used which were described in details in Asseng et al. (2013). The locations were Wageningen - NL (Groot et al., 1991), Balcarce - AR (Travasso et al., 1995), New Delhi - IN (Naveen, 1986), and Wongan Hills - AU (Asseng et al., 1998). In particular, the experimental sites were defined in terms of yield and season length as high yielding and long season in the $\mathrm{NL}$, high/medium yielding and medium season in AR, irrigated and short season in IN, and low yielding, rainfed, short season in AU (Asseng et al., 2013). These locations were chosen to represent four different wheat mega-environments, a concept used by wheat breeders for testing cultivars (Monfreda et al., 2008) that accounts for about $80 \%$ of the wheat-growing area of the world (Additional details were provided in Tables S1 and S2).

The data were quality controlled and standardized using the AgMIP data protocols (Rosenzweig et al., 2011). The management information used at each site was obtained from the experimentalists. The crops were kept weed and disease-free. Daily weather data of solar radiation, maximum and minimum temperature and rainfall were recorded at weather stations on site, with the exception of IN, where solar radiation was obtained from the NASA POWER dataset (White et al., 2011b). At NL, the average daily wind speed at 2-m height was measured. At the three other locations daily wind speed was estimated using the NASA Modern Era RetrospectiveAnalysis for Research and Applications (MERRA) (Rienecker et al., 2011). At all locations dew-point temperature was estimated using MERRA. Atmospheric $\left[\mathrm{CO}_{2}\right]$ was assumed to be at $360 \mathrm{ppm}$ for all the locations, in line with measured atmospheric $\left[\mathrm{CO}_{2}\right]$ for the midpoint (year 1995) of the baseline climate period 1980-2009.

Measured experimental field data used for this study were harvested grain dry matter yield $\left(Y\right.$, t ha $\left.^{-1}\right)$, in-season measurements of total aboveground biomass (dry matter) (AGB; tha ${ }^{-1}$ ), leaf area index $\left(\mathrm{LAI}, \mathrm{m}^{2} \mathrm{~m}^{-2}\right)$, water use (WU, $\left.\mathrm{mm}\right)$, and soil water content to maximum rooting depth (SWC, Vol\%). For each location soil the soil layers were supplied to all modelling groups (Table S2). For each soil layer ( $i$ for up to $n$ layers) and from the layer-specific SWC, the plant available soil water content to maximum rooting depth (PAW, $\mathrm{mm}$ ) was calculated using the lower limit of water extraction for each soil layer (LL, Vol\%) which is similar to the soil moisture content at wilting point, and the thickness of each soil layer (st, m) as follows:

$P A W=\sum_{i=1}^{n} s t_{i} *\left(S W C_{i}-L L_{i}\right)$

At NL, the SWC was measured down to $1 \mathrm{~m}$, so the SWC and PAW were calculated assuming that the soil between $1 \mathrm{~m}$ and maximum rooting depth of $2 \mathrm{~m}$ was similar to the $0.6-1 \mathrm{~m}$ layers. At AR, 

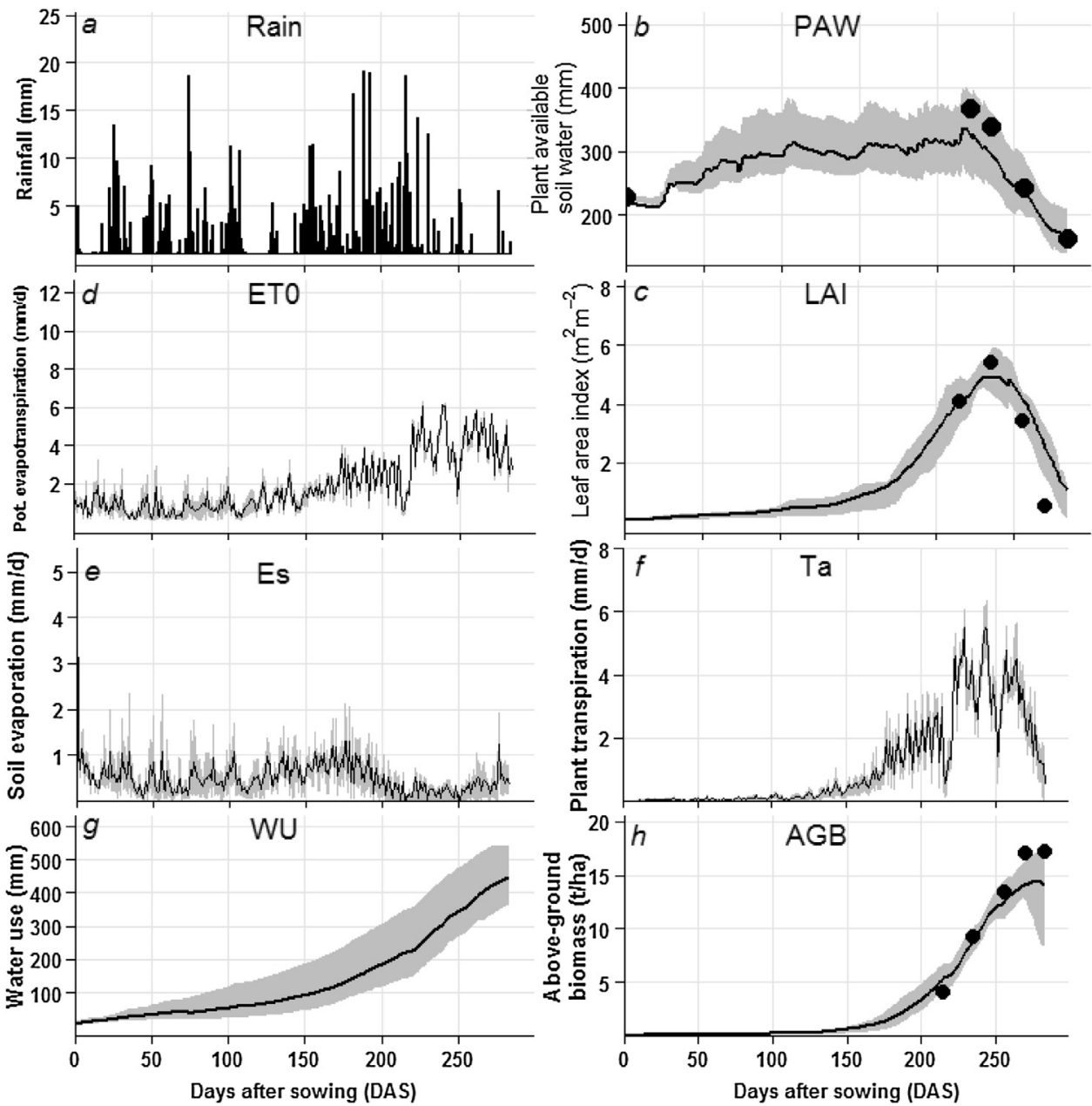

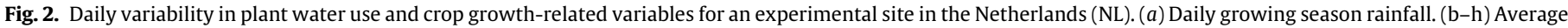

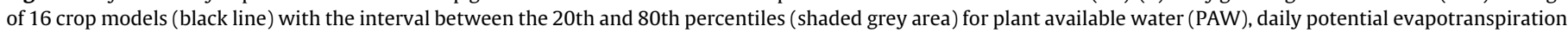

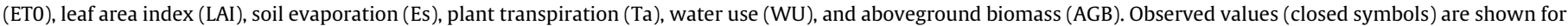
plant available soil water, LAI, and above-ground biomass.

the SWC was measured down to $1.2 \mathrm{~m}$ and the maximum rooting depth was $1.3 \mathrm{~m}$. While, in IN and AU the SWC was measured up to $1.5 \mathrm{~m}$ and $2.1 \mathrm{~m}$, and the maximum rooting depth was 160 and 210 , respectively.

Soil water balance (SWB) was calculated for each simulation run using the simulated drainage $(\mathrm{mm})$, runoff $(\mathrm{mm})$, crop transpiration ( $\mathrm{mm}$ ), soil evaporation ( $\mathrm{mm}$ ), and rainfall ( $\mathrm{mm}$ ) for $\mathrm{NL}, \mathrm{AR}, \mathrm{AU}$, while for IN irrigation was also considered $(\mathrm{mm})$. To calculate the $\Delta$ Soil Water Change (SWB) the following equation was used:

SWB $=$ Rain + Irrigation - Drainage - Runoff - Transpiration

- Evaporation

\subsection{Crop models}

Based on a twenty-six member multi-model ensemble study conducted by Asseng et al. (2013), sixteen crop models which simulate crop transpiration ( $\mathrm{Ta}$ ) and soil evaporation (Es) as separate fluxes were selected for detailed analysis of water use simulations (for more detailed information on the simulated processes see Table S3). The models, which varied in complexity and functionalities, have all been described and used in modelling wheat crops. Additional details on modelling procedures were described in Asseng et al. (2013), for this study we used the models calibrated against phenology and yield. At the beginning of the study a questionnaire was sent to the modelers to provide information on which type of $E T_{0}$ was used in the crop models. Information on different implementations of the $E T_{0}$ calculation in the 16 wheat models using the Penman (P; Penman, 1948), Penman-Monteith (PM; Allen et al., 1998) or Priestley-Taylor (PT; Priestley and Taylor, 1972) equations (Table S3). Analysis of variance (ANOVA) for unbalanced designs was used to test the differences among the three $E T_{0}$ formulas at each location.

\subsection{Data analysis}

The partitioning of uncertainty of simulated WU was made to explore which component was responsible for most of the variability. WU can be expressed as follows, based on simulated cumulative $\Sigma E T_{0}, \Sigma T a$ and $\Sigma E s$ :

$\mathrm{WU}=\sum E T o *\left[\frac{\sum E s}{\sum E T o}+\frac{\sum T a}{\sum E T o}\right]$

The variance is calculated as follows:

$\operatorname{Var}(\mathrm{WU})=\operatorname{Var}\left(\frac{\sum T a}{\sum E T o}\right) * E\left(\sum E T o\right)^{2}+\operatorname{Var}\left(\frac{\sum E s}{\sum E T o}\right)$ 

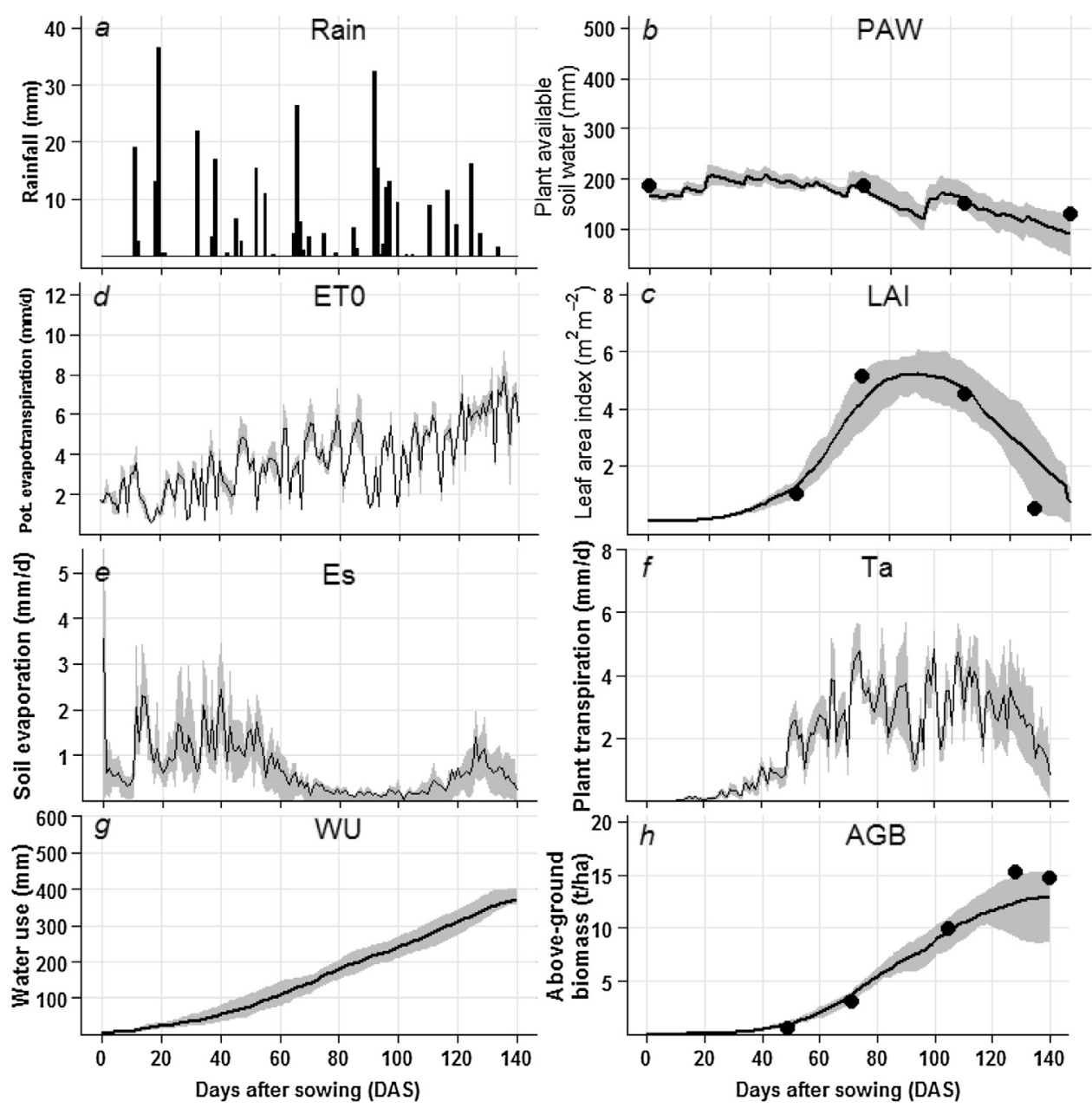

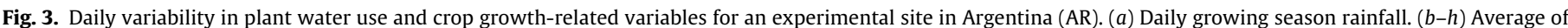

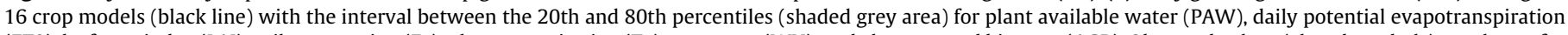

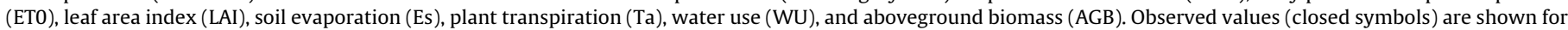
plant available soil water, LAI, and above-ground biomass.

$$
* E\left(\sum E T o\right)^{2}+\operatorname{Var}\left(\sum E T o\right) *\left[E\left(\frac{\sum E s}{\sum E T o}+\frac{T a}{\sum E T o}\right)\right]^{2}
$$

where $\sum T a / \sum E T o$ was transpiration as a fraction of evaporative demand and $\sum E s / \sum E T o$ was soil evaporation as a fraction of evaporative demand. A way of quantifying the contribution of $\sum T a / \sum E T o, \sum E s / \sum E T o$, and $\Sigma E T_{0}$ to the overall uncertainty was through the first-order sensitivity coefficients (S1):

$$
\begin{aligned}
& S 1(T a)=\operatorname{Var}\left(\sum T a / \sum E T o\right) * E\left(\sum E T o\right)^{2} \\
& S 1(E s)=\operatorname{Var}\left(\sum E S / \sum E T o\right) * E\left(\sum E T o\right)^{2} \\
& S 1(E T o)=\operatorname{Var}\left(\sum E T o\right) *\left[E\left(\sum E s / \sum E T o+\sum T a / \sum E T o\right)\right]^{2}
\end{aligned}
$$

If there are no interactions among terms, $\mathrm{S} 1(x)$ is the fraction of overall variance contributed by factor $x$ and the sum of the S1 can be somewhat larger or smaller than 1 , depending on whether there were positive or negative correlations between terms. The larger the values of $S 1(x)$, the greater the contribution of factor $x$ to the overall variance. From the sum of the first-order sensitivity coefficients, we calculated the percentage contribution of each term.
Water use efficiency (WUE) was calculated as:

$$
\text { WUE }=\frac{Y}{\Sigma W U}
$$

where $Y$ is the simulated grain dry matter yield and $\Sigma W U$ was the cumulative evapotranspiration calculated from sowing to harvest. Transpiration efficiency ( $T_{\text {eff }}$ ) on a grain yield basis was calculated following the definition of Angus and van Herwaarden (2001):

$T_{\text {eff }}=\frac{Y}{\sum T a}$

where $\Sigma T a$ is the cumulative water transpired from sowing to harvest.

\subsection{Sensitivity analysis}

In addition to the simulations based on the measured experimental conditions, simulations were conducted using daily weather data for the period 1980-2010 for all the locations to create a baseline. A sensitivity analysis of the sixteen models to temperature and $\left[\mathrm{CO}_{2}\right]$ was done using a partly-factorial design. Daily minimum and maximum temperature were increased by either $3{ }^{\circ} \mathrm{C}(+3 \mathrm{C})$ or $6{ }^{\circ} \mathrm{C}(+6 \mathrm{C})$ and $\left[\mathrm{CO}_{2}\right]$ was increased in $90 \mathrm{ppm}$ increments from a baseline to a maximum of $720 \mathrm{ppm}$. Wind speed and relative humidity were kept unchanged with the increased temperatures, so vapor pressure was re-calculated using the modified 

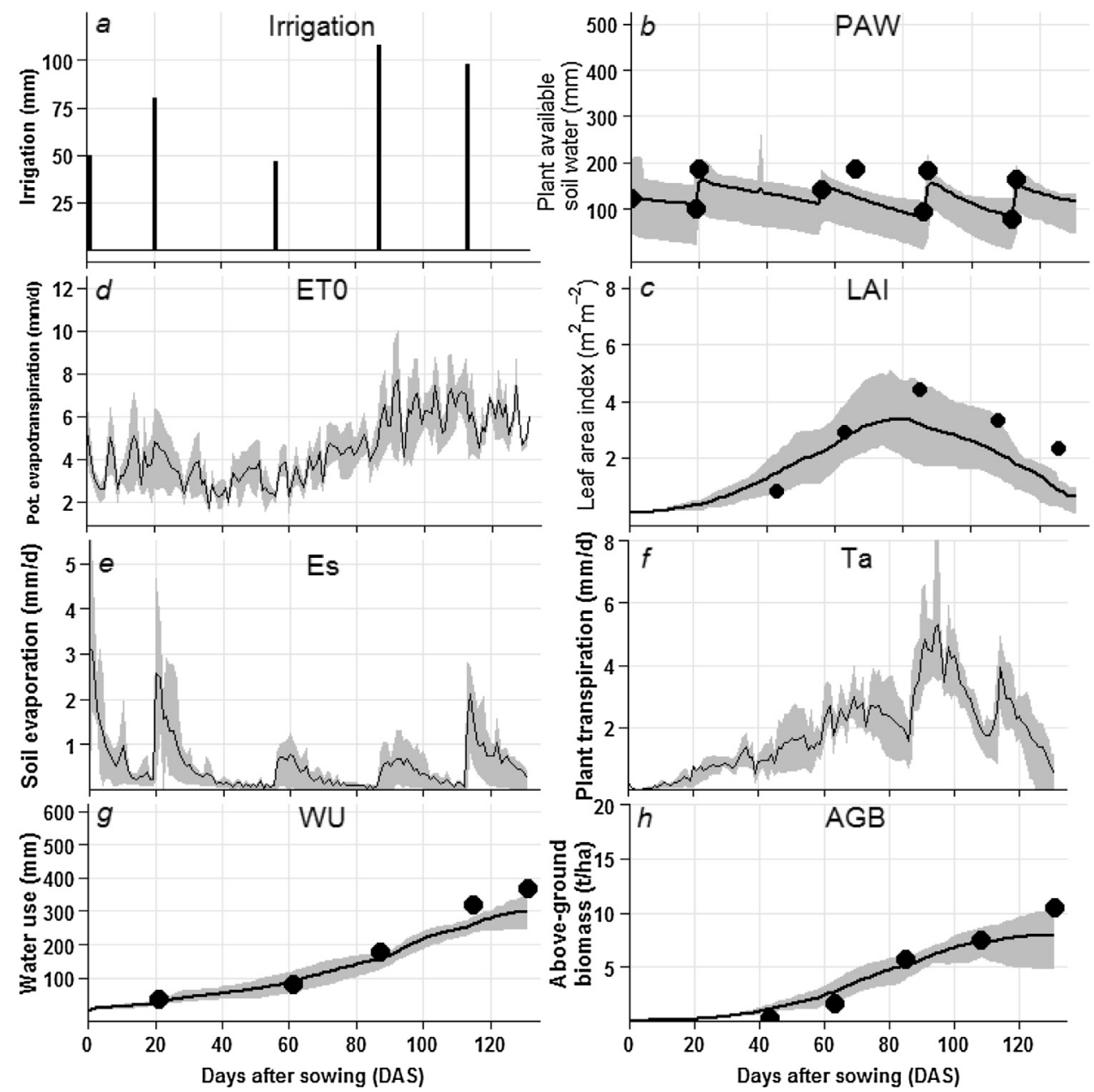

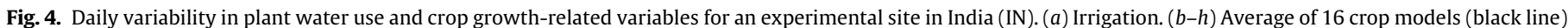

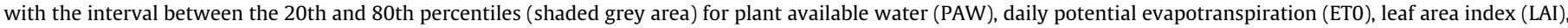

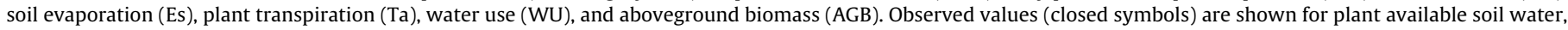
LAI, water use, and above-ground biomass.

temperatures. In order to understand the effects of climate factors alone on crop responses, soil and crop management were kept the same for all the simulations except that dates of irrigation and fertilization were adapted to the changed phenology.

The relative changes in $Y, \mathrm{WU}, T a, E s$, WUE, and $T_{\text {eff }}$ were calculated as:

$r_{k}=\frac{\bar{y}_{\text {sensitivity }, k}-\bar{y}_{\text {baseline }, k}}{\bar{y}_{\text {baseline }, k}} * 100$

where $r_{k}$ is the predicted relative change with respect to the 30year baseline according to model $k, \bar{y}_{\text {sensitivity, } k}$ is any of the above variables averaged over the 30 years of climate sensitivity according to model $k$, and $\bar{y}_{\text {baseline, },}$ are the variables averaged over the 30 years of baseline climate according to model $k$.

More detailed analysis of the multi-model intercomparison in terms of decomposition of the mean square error and other statistical indicators can be found in Martre et al. (2015).

\section{Results}

\subsection{Decomposition of the variability}

The simulated growing season $E T_{0}$ using the three methods (PM, PT, and P) ranged from $786 \mathrm{~mm}$ for AU to $483 \mathrm{~mm}$ for the NL(Fig. 1a).
Total season $E T_{0}$ values calculated by the three methods differed at each location ( $P<0.05$; Fig. 1a).

When the uncertainty of simulated WU was partitioned between $T a, E s$, and $E T_{0}$, and following equations [2] to [6], the first-order sensitivity coefficient $\mathrm{S} 1(\mathrm{Ta})$ contributed the most to the variability in WU among models (Fig. 1b-d). For the single year dataset the term $\mathrm{S} 1(\mathrm{Ta})$ was $46 \%$ of the variability, $\mathrm{S} 1(\mathrm{Es})$ was $30 \%$, and $\left(E T_{0}\right)$ was $24 \%$ (Fig. $1 \mathrm{~b}$ ). For the simulations averaged over the 30 -year baseline, $S 1(\mathrm{Ta}), \mathrm{S} 1(\mathrm{ES})$, and $\mathrm{S} 1\left(E T_{0}\right)$ were $51 \%, 28 \%$ and $21 \%$, respectively (Fig. 1b). There was little change in the first order sensitivity coefficients as temperature increased. The S1(Ta), S1(Es), and $S 1\left(E T_{0}\right)$ values were 46,37 , and $18 \%$ at $+3 C$ and 50,36 and $14 \%$ at $+6 \mathrm{C}$ ( Fig. 1c). Simulations with four $\left[\mathrm{CO}_{2}\right]$ showed similar results with $\mathrm{S} 1(\mathrm{Ta})$ ranging between 53 and 54\% (Fig. 1d).

\subsection{Observed and simulated data}

The daily patterns of growing season rainfall, observed and simulated PAW, $E T_{0}$, LAI, Es, Ta, WU, and AGB are shown for NL, AR, IN, and $A U$ in Figs. $2-5$, respectively. The four wheat-growing locations differed in terms of the evaporative demand of the atmosphere, soil conditions, and the temporal variability of growing season rainfall and temperature (Figs. 2-5). For example, at AU rainfall occurred frequently throughout the season with occasional days of heavy rainfall in spring and summer (Fig. 5a). In contrast, there was no 

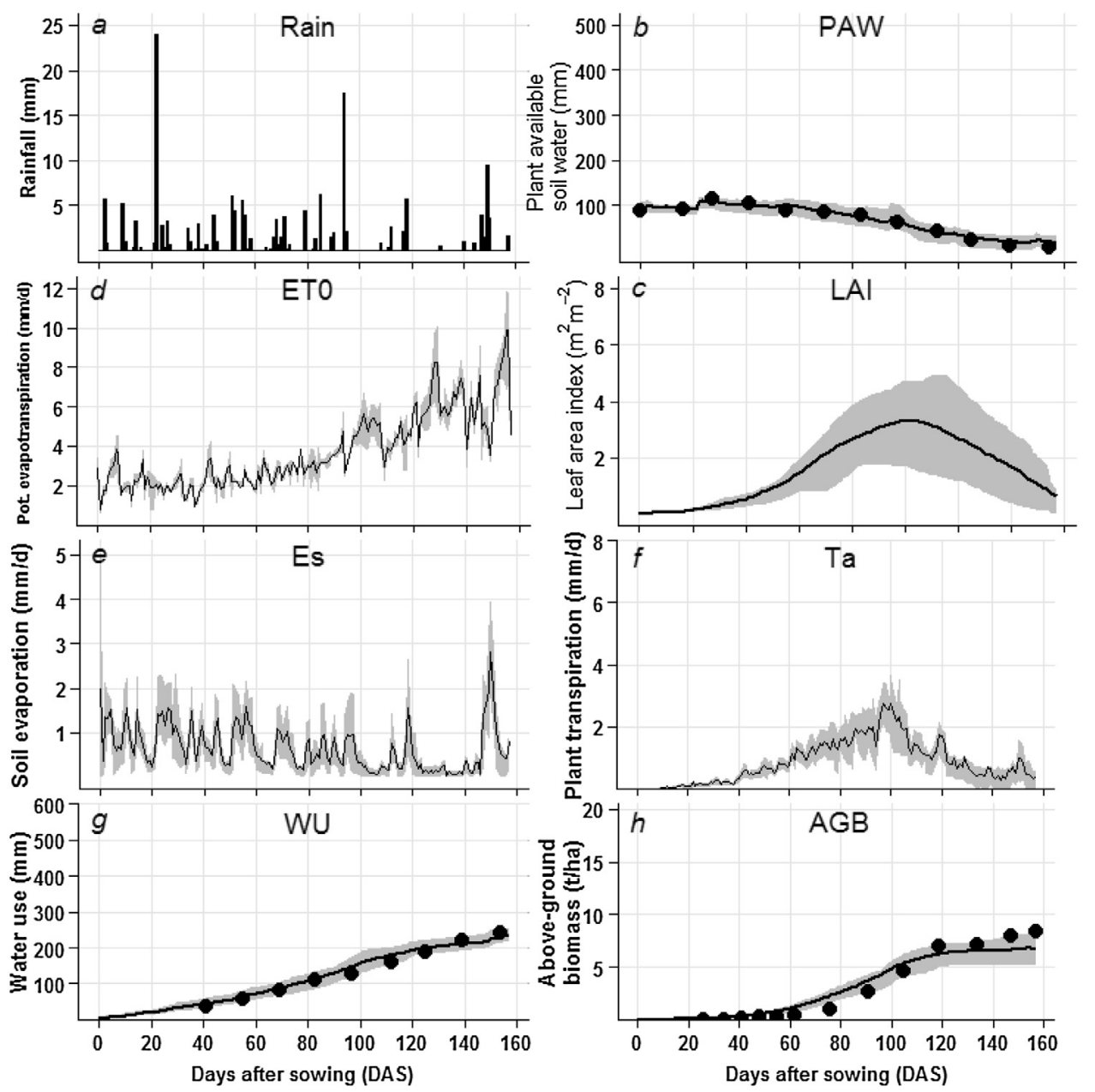

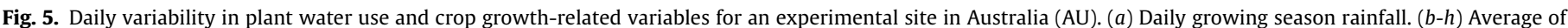

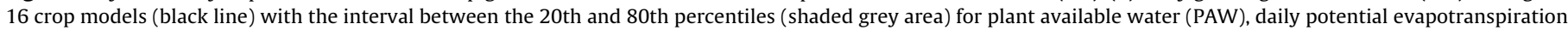

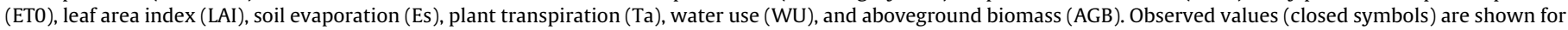
plant available soil water, water use, and above-ground biomass.

rainfall at the IN site (Fig. 4a). NL and AR had frequent heavy rainfall during the growing season (Figs. $2 \mathrm{a}$ and $3 \mathrm{a}$ ). The in-season observed values for the plant available soil water, aboveground biomass, water use, and LAI were within the range of the simulations in NL, AR, and AU (Figs. 2, 3 and 5). There were some discrepancies between observed and simulated values in IN for the LAI, PAW and WU (Fig. 4).

The end-of-season cumulative WU, WUE, Ta, Es, $T_{\text {eff }}$, and $Y$ for the single experimental year, and for the 30-year period from 1980 to 2009 are shown in Table 1 . Simulated average values for WU was less variable than for WUE and $T_{\text {eff }}$. The coefficient of variation (CV) across locations for the single experimental year varied between 14 and 23\% for WU, and between 16 and 37\% for WUE. Average CV of simulated values varied between 20 and 33\% for $\mathrm{Ta}$, between 34 and $73 \%$ for $E s$, and between 24 and $55 \%$ for $T_{\text {eff }}$ (Table 1 ).

\subsection{Crop simulation models sensitivity to average daily air temperature and atmospheric $\mathrm{CO}_{2}$ concentration}

The average simulated WU, $Y, T a, E s$, WUE, and $T_{\text {eff }}$ decreased with increased temperature for all four locations (Fig. 6). However, the variability of the models increased as temperature increased for all the variables (Fig. 6). The models showed higher uncertainties for Australia, where except for the simulated WU which had little variability. In Australia simulated $\mathrm{T}_{\text {eff }}$ varied between -100 and $+100 \%$ when temperature was increased by $+6 \mathrm{C}$ (Fig. 6 ).

Simulated average WU, $\mathrm{Ta}$, and Es decreased with increasing $\left[\mathrm{CO}_{2}\right]$ while $\mathrm{Y}$, WUE, and $T_{\text {eff }}$ increased with increasing $\left[\mathrm{CO}_{2}\right]$ at all locations (Fig. 7). The simulated relative changes to $\left[\mathrm{CO}_{2}\right]$ showed less variability than temperature. This outcome seemed to be consistent across the models, with the exception of few outliers. At 720 compared to $360 \mathrm{ppm}\left[\mathrm{CO}_{2}\right]$ in the four locations, the overall simulated values changed by $-4 \%$ for $\mathrm{WU},+31 \%$ for $Y,-2 \%$ for $\mathrm{Ta},-9 \%$ for $E s,+38 \%$ for WUE, and $+34 \%$ for $T_{\text {eff }}$ (Fig. 7 ). Only the variability of WUE and Teff was higher at $720 \mathrm{ppm}$ than at $360 \mathrm{ppm}$, ranging between 0 and $100 \%$ changes at 720 ppm (Fig. 7).

The respective effects of changing temperature and $\left[\mathrm{CO}_{2}\right]$ interact in generating model outputs of the 16 crop models. For simulated $W U$, increasing $\left[\mathrm{CO}_{2}\right]$ to $720 \mathrm{ppm}$ does not offset its reduction caused by temperature increase (Fig. 8). The effects of $\left[\mathrm{CO}_{2}\right]$ in compensating temperature-induced losses of WUE and $T_{\text {eff }}$ were larger than for simulated $W U$ (Fig. 8). For example, with a $6^{\circ} \mathrm{C}$ increase, WUE increased if $\left[\mathrm{CO}_{2}\right]$ was above $450 \mathrm{ppm}$ in NL and IN, or above $550 \mathrm{ppm}$ in AR and AU (Fig. 8).

Of particular interest is the variability in the direction of change in simulated responses to increased temperature or $\left[\mathrm{CO}_{2}\right]$. It was studied by counting how many models showed similar trend; for example how many models simulated a decrease in WU at $+6 C$, and how many simulated an increase in $\mathrm{WU}$ at $+6 \mathrm{C}$. Overall, with a 


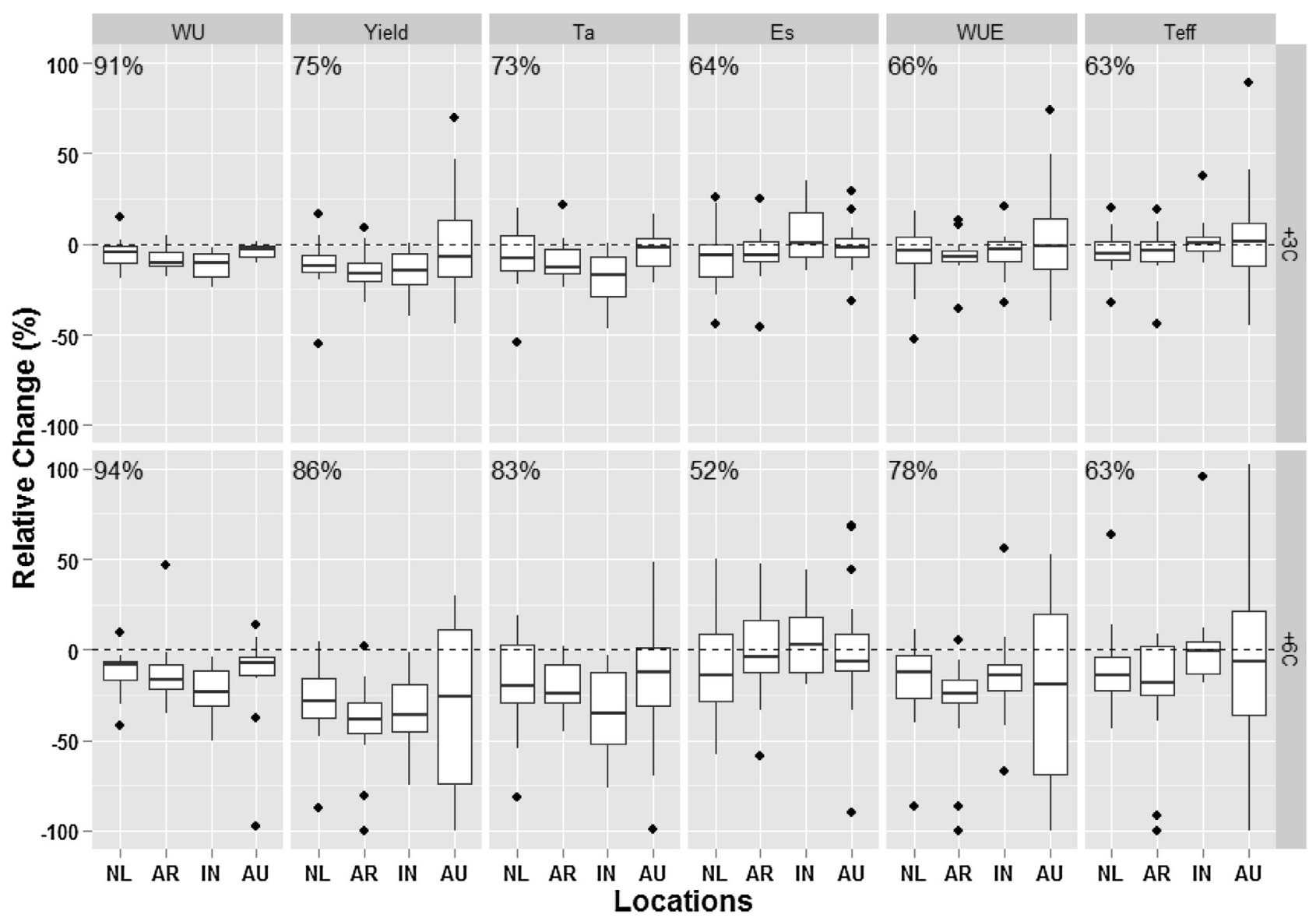

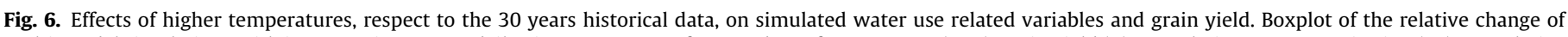

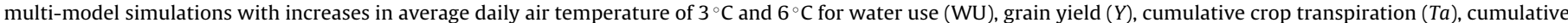

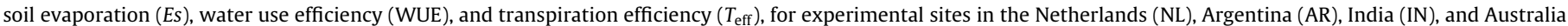
(AU). The percentage of individual models that predict the same trend is shown above each set of points.

Table 1

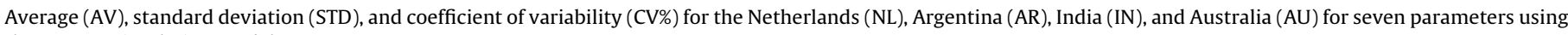
the 16 crop simulation models.

\begin{tabular}{|c|c|c|c|c|c|c|c|c|c|c|c|c|c|}
\hline \multirow{2}{*}{$\begin{array}{l}\text { Variable } \\
\text { 1-Year }\end{array}$} & \multirow[t]{2}{*}{ Unit } & \multirow{2}{*}{$\begin{array}{l}\mathrm{AV} \\
\mathrm{NL} \\
\end{array}$} & \multirow[t]{2}{*}{ STD } & \multirow[t]{2}{*}{ CV\% } & \multirow{2}{*}{$\begin{array}{l}\mathrm{AV} \\
\mathrm{AR}\end{array}$} & \multirow[t]{2}{*}{ STD } & \multirow[t]{2}{*}{ CV\% } & \multirow{2}{*}{$\begin{array}{l}\text { AV } \\
\text { IN } \\
\end{array}$} & \multirow[t]{2}{*}{ STD } & \multirow[t]{2}{*}{ CV\% } & \multirow{2}{*}{$\begin{array}{l}\mathrm{AV} \\
\mathrm{AU}\end{array}$} & \multirow[t]{2}{*}{ STD } & \multirow[t]{2}{*}{$\mathrm{CV} \%$} \\
\hline & & & & & & & & & & & & & \\
\hline ET0 $^{\mathrm{a}}$ & $(\mathrm{mm})$ & 548.8 & 92.7 & 16.9 & 516.7 & 56.4 & 10.9 & 590.1 & 92.6 & 15.7 & 647.2 & 68.4 & 10.6 \\
\hline$W^{\mathrm{b}}$ & $(\mathrm{mm})$ & 445.4 & 100.3 & 22.5 & 371.3 & 51.7 & 13.9 & 301.9 & 49.9 & 16.5 & 234 & 38.4 & 16.4 \\
\hline$T_{a}{ }^{\mathrm{c}}$ & $(\mathrm{mm})$ & 301.7 & 85.7 & 28.4 & 271.6 & 53.9 & 19.8 & 232.5 & 66.3 & 28.5 & 132.1 & 43.8 & 33.2 \\
\hline$E_{s}^{\mathrm{d}}$ & $(\mathrm{mm})$ & 143.7 & 60.6 & 42.2 & 99.6 & 33.4 & 33.5 & 69.4 & 50.7 & 73.1 & 101.9 & 39.8 & 39.1 \\
\hline Yield & $\left(\mathrm{tha}^{-1}\right)$ & 7.7 & 0.4 & 5.7 & 6.1 & 0.5 & 9 & 4 & 0.4 & 10.4 & 2.2 & 0.5 & 21.9 \\
\hline WUE ${ }^{e}$ & $\left(\mathrm{~kg} \mathrm{ha}^{-1} \mathrm{~mm}^{-1}\right)$ & 18.1 & 4.1 & 22.6 & 16.6 & 2.6 & 15.6 & 13.8 & 2.6 & 19 & 9.9 & 3.7 & 37.3 \\
\hline $\mathrm{T}_{\text {eff }}^{\mathrm{f}}$ & $\left(\mathrm{kg} \mathrm{ha}^{-1} \mathrm{~mm}^{-1}\right)$ & 29.2 & 16 & 55 & 23.3 & 5.6 & 24 & 19.3 & 7.4 & 38.4 & 18.9 & 8.2 & 43.2 \\
\hline \multicolumn{14}{|c|}{ Baseline (30-years) } \\
\hline ET0 & $(\mathrm{mm})$ & 556.7 & 88.3 & 15.9 & 539.6 & 55.4 & 10.3 & 564.6 & 68.7 & 12.2 & 692.7 & 68.8 & 9.9 \\
\hline WU & $(\mathrm{mm})$ & 449.9 & 99.3 & 22.1 & 365.9 & 58.9 & 16.1 & 329.4 & 52 & 15.8 & 258.6 & 49.7 & 19.2 \\
\hline$T_{a}$ & $(\mathrm{~mm})$ & 297.9 & 75.3 & 25.3 & 257 & 50.1 & 19.5 & 244.8 & 62.9 & 25.7 & 154.4 & 46.9 & 30.4 \\
\hline$E_{s}$ & $(\mathrm{~mm})$ & 152 & 56.9 & 37.5 & 109 & 35.9 & 33 & 84.7 & 46.7 & 55.1 & 104.2 & 44.2 & 42.4 \\
\hline Yield & $\left(\right.$ tha $\left.^{-1}\right)$ & 7.4 & 0.9 & 12.3 & 5.5 & 0.4 & 8 & 5 & 0.6 & 12.2 & 2.8 & 0.6 & 21.4 \\
\hline WUE & $\left(\mathrm{kg} \mathrm{ha}^{-1} \mathrm{~mm}^{-1}\right)$ & 17.3 & 4.9 & 28.1 & 15.6 & 3.2 & 20.5 & 15.4 & 1.8 & 11.6 & 11.3 & 4.2 & 36.7 \\
\hline $\mathrm{T}_{\text {eff }}$ & $\left(\mathrm{kg} \mathrm{ha}^{-1} \mathrm{~mm}^{-1}\right)$ & 27.5 & 13.4 & 48.6 & 22.5 & 5.8 & 25.9 & 21.9 & 6.7 & 30.5 & 20.4 & 10.1 & 49.3 \\
\hline
\end{tabular}

a Potential evapotranspiration.

b Water use.

c Crop transpiration.

d Soil evaporation.

e Water use efficiency.

f Transpiration efficiency. 


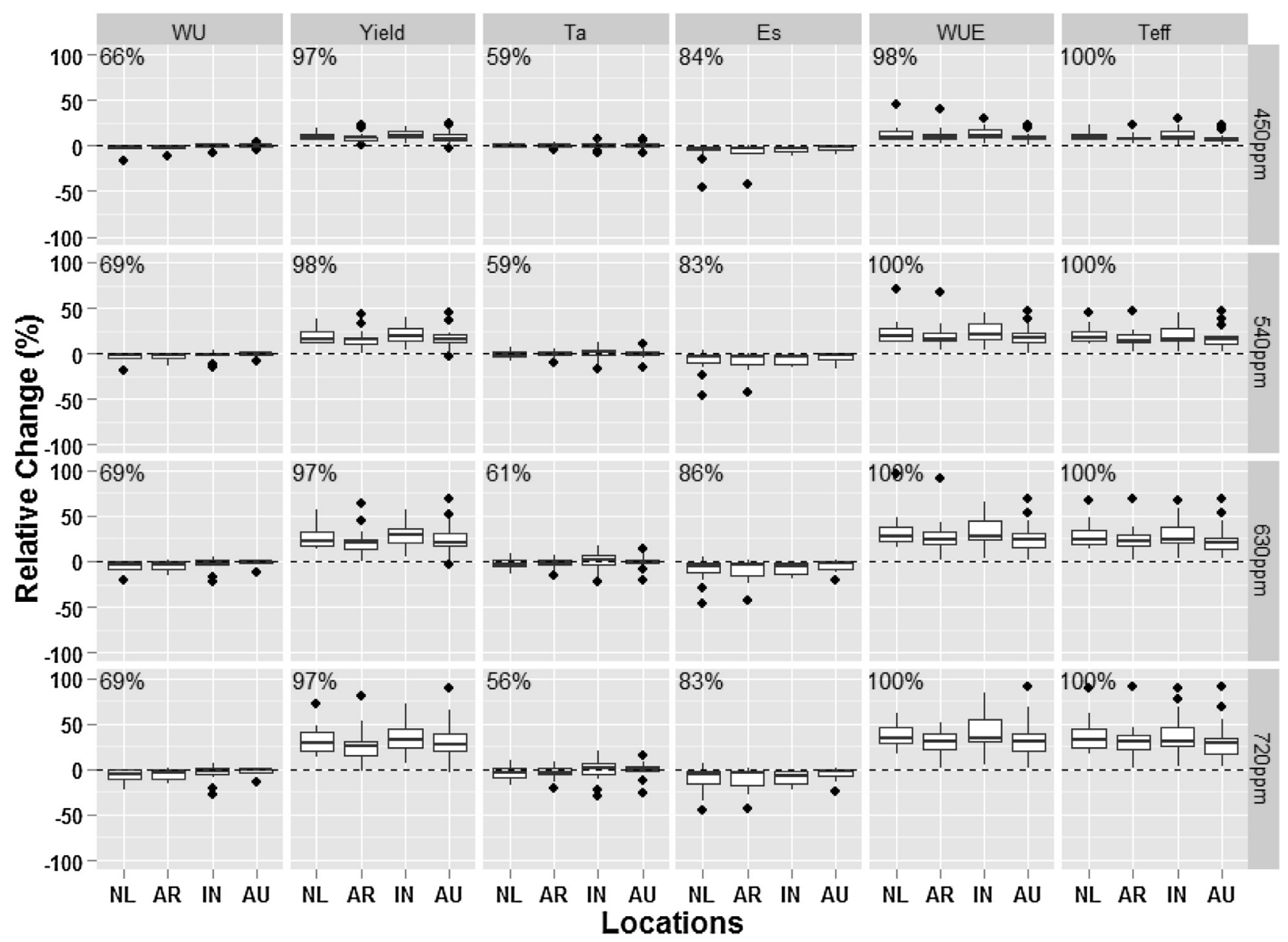

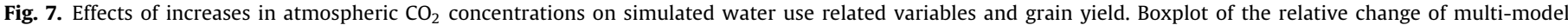

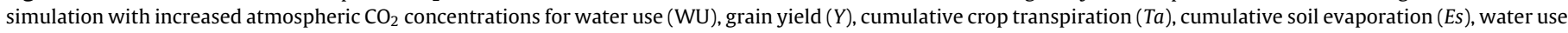

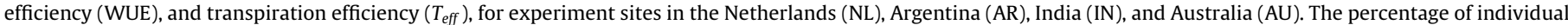
models that predict the same trend as the multi-model mean is shown above each set of points.

$6{ }^{\circ} \mathrm{C}$ increase across the four locations, $94 \%$ of the models computed that WU decreased, $83 \%$ that Ta decreased, 52\% that Es decreased, $78 \%$ that WUE decreased, and $63 \%$ that $\mathrm{T}_{\text {eff }}$ decreased (Fig. 6). Modelling the effect of $720 \mathrm{ppm} \mathrm{CO}_{2}, 69 \%$ of the models agreed that WU decreased, 97\% that $Y$ increased, 56\% that Ta decreased, and $83 \%$ that Es decreased. All models projected that WUE and $\mathrm{T}_{\text {eff }}$ would increase (Fig. 7).

The calculated SWB using Eq. (2) showed that for both baseline and sensitivity to temperature and $\mathrm{CO}_{2}$ the NL had a higher variability among the models with respect to the other locations (Fig. 9). The variability among the different components of Eq. (2) showed that transpiration (Ta) was the component having the higher variability followed by the drainage (Fig. 10). For example, in the NL the simulated transpiration varied between 100 and $500 \mathrm{~mm}$ for the baseline runs (No temperature changes) and drainage between 0 and $400 \mathrm{~mm}$, for the upper and lower hinge representing the 25th and 75 th percentile, respectively. At $+6 \mathrm{C}$ the variability of simulated crop transpiration among models ranged between 10 and $540 \mathrm{~mm}$ while simulated drainage ranged between 0 and $350 \mathrm{~mm}$ (Fig. 10a).

\section{Discussion}

In this study, most of the variability in simulated WU was due to model differences in Ta/ETo and Es/ETo rather than the choice of the $E T_{0}$ formula. This is true for the experimental years, the 30year baseline and for the simulations with increased temperature or $\mathrm{CO}_{2}$. While differences in the choice of the $E T_{0}$ formula have been shown to be important (Kingston et al., 2009; McAfee, 2013; McKenney and Rosenberg, 1993; Utset et al., 2004; Xu and Singh, 2002), studies focusing on the $E T_{0}$ formula have not analyzed how the partitioning of $E T_{0}$ between $E s$ and $T a$ would influence the simulations of crop WU. Other studies have focused on the partitioning within the growing season of the Es and Ta only, showing that Es can account for $20 \%$ to $40 \%$ of WU (Kool et al., 2014; French and Schultz, 1984).

Although the overall first order effect of Ta/ETo accounted for $51 \%$ of the total of first order effects on WU for both different temperature and $\mathrm{CO}_{2}$ changes across the four locations, no experimental data were available to validate these aspects of the simulation. Differences among models in simulating rooting depth/distribution and soil water extraction by roots could be an important reason for differences in $\mathrm{Ta}$ estimation (Wu and Kersebaum, 2008).

Understanding the partitioning of WU between crop transpiration and soil evaporation is critical because of its implications for agricultural, ecological, and hydrological studies. In addition, considering the variability in the simulation of PAW, and particularly of simulated LAI, the differences in Ta/ETo are not surprising because the water is transpired by crops through stomata that are on leaves.

Given the variability of the simulated SWB, and of the other components like drainage, further research into the reasons of variation of different sub-routines among models is necessary. The 

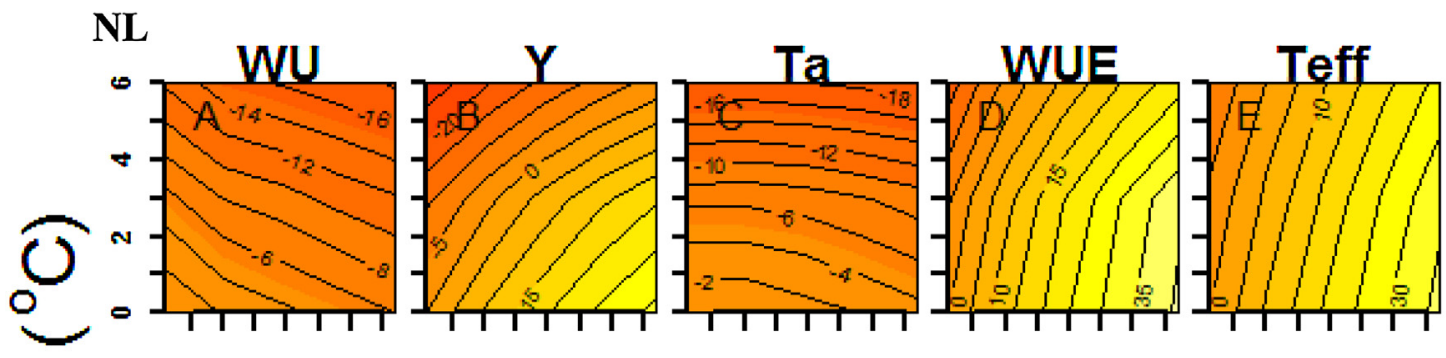

Relative
Change
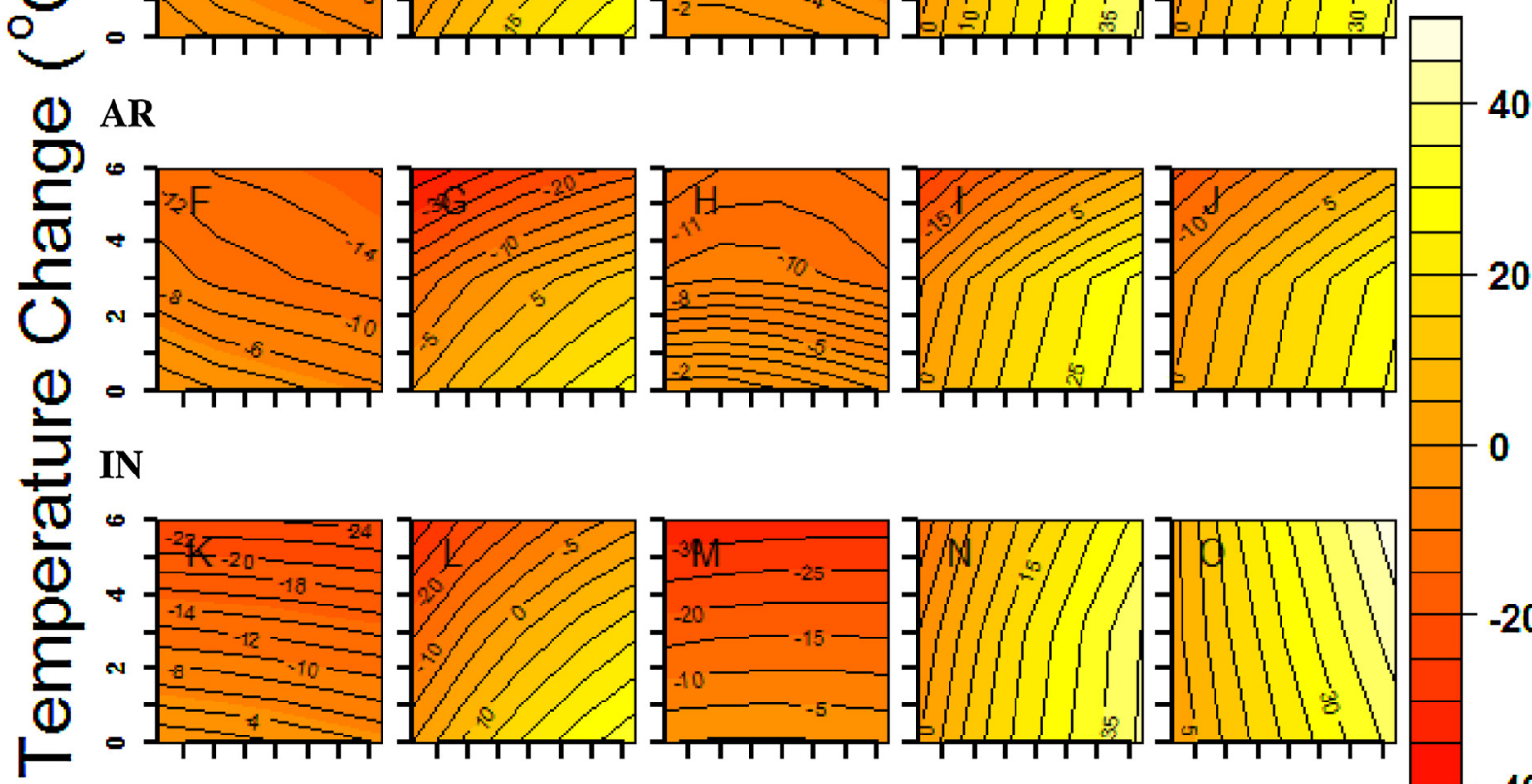

AU
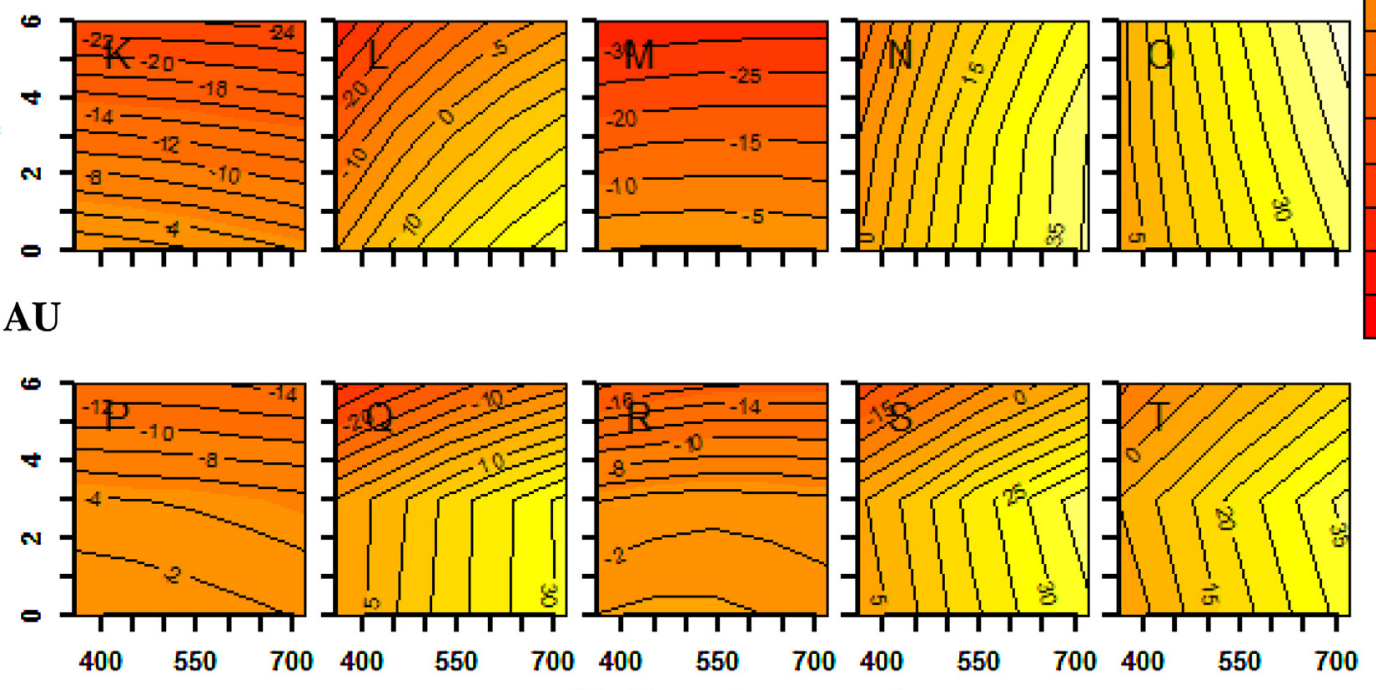
$\mathrm{CO}_{2}(\mathrm{ppm})$

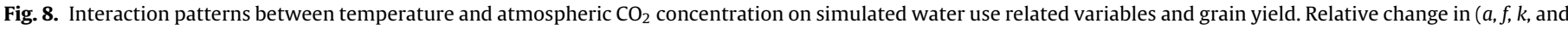

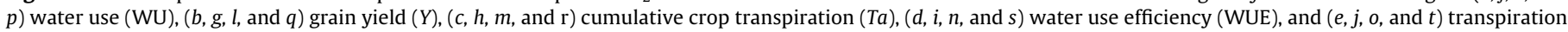

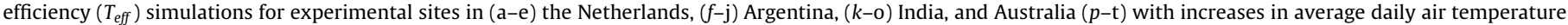
versus atmospheric $\mathrm{CO}_{2}$ concentration.

hardest part is to get detailed and accurate measurements of each sub-component in a single experiment.

The large variability between models indicates that there are major differences in the way the processes that affect water use are modeled. Differences among models in simulating soil water extraction by roots could be an important reason for differences in Ta estimation (Wu and Kersebaum, 2008). Variability in the simulation of PAW and LAI would have a direct effect on the differences in $T a / E T_{0}$. Since PAW was among the given soil parameters, causes are primarily related to differences in the models' crop interfaces to soil (roots) and atmosphere (LAI).

Models have been tested against the same limited set of $\mathrm{CO}_{2}$ response data, which are from open-top chamber or Free Air Carbon dioxide Enrichment Experiments (FACE) data. Models also typically include many processes that respond to temperature, while the response to $\mathrm{CO}_{2}$ is often lumped at a higher level of integration as discussed in details by Kersebaum and Nendel (2014). Some models used an empirical relationship between $\mathrm{CO}_{2}$ and radiation use efficiency while other models used the $\mathrm{CO}_{2}$ dependency of the photosynthesis light response curve (Tubiello and Ewert, 2002) or directly simulated stomatal conductance and rubisco-kinetics based photosynthesis.

However, there is no clear relationship between model results and model's structure because models are complex and many elements of structure interact with each other (Bassu et al., 2014; Li et al., 2015; Martre et al., 2015). Further research into the sources of variation of different sub-routines among models is necessary.

Increased $\left[\mathrm{CO}_{2}\right]$ in field crops has led to decreases in WU of 3-8\%, and an increase in $Y$ of 8-31\% (Hatfield et al., 2011; Kimball et al., 2002; Long et al., 2006; Manderscheid and Weigel, 2007; Tao and Zhang, 2013). The variability in the experimental results depends on crop management, $\mathrm{CO}_{2}$ concentrations used in the experiments, the type of experiment (e.g. open-top chambers or field experiments), and the different scaling methods used to compare a crop 
a)

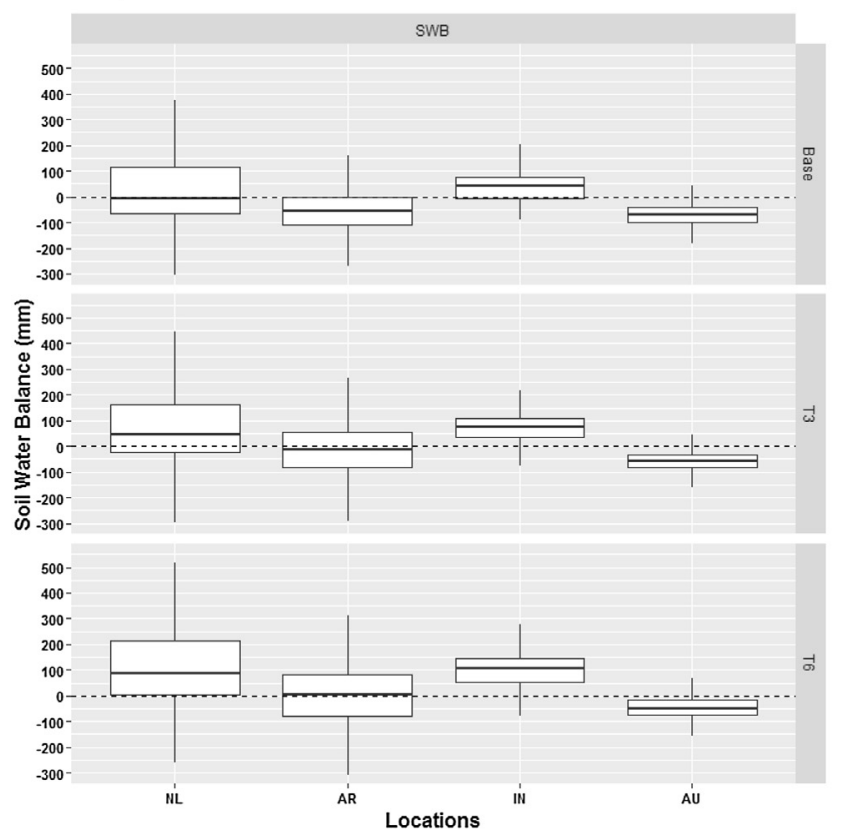

b)

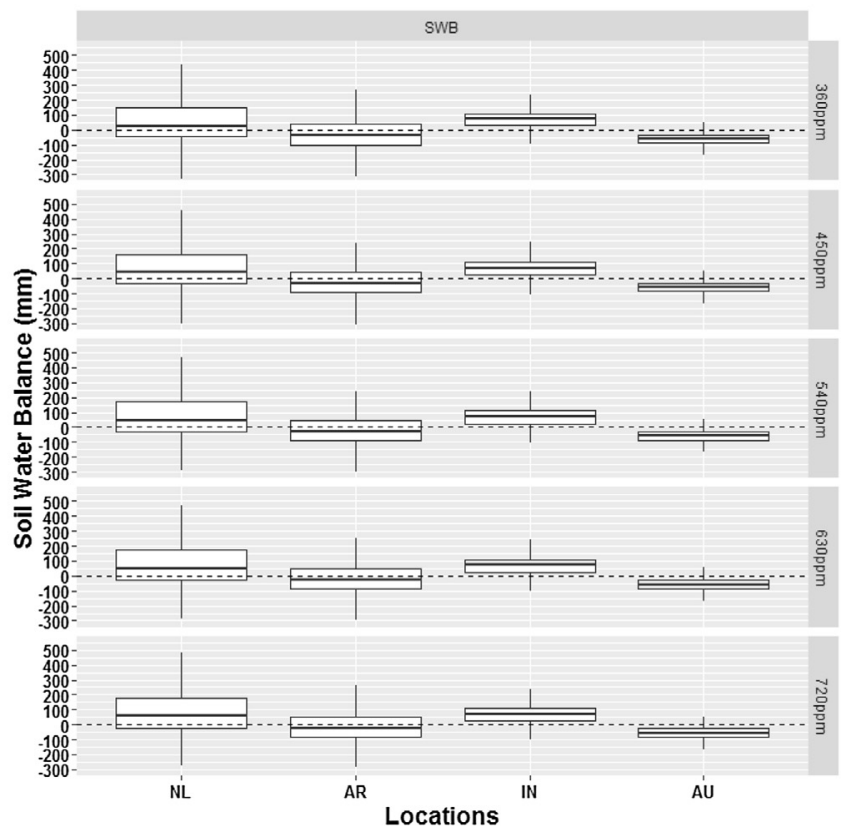

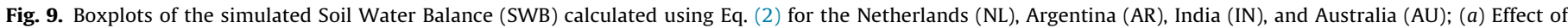

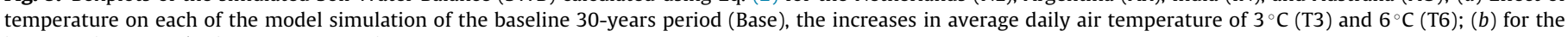
increases in atmospheric $\mathrm{CO}_{2}$ concentrations.

a)

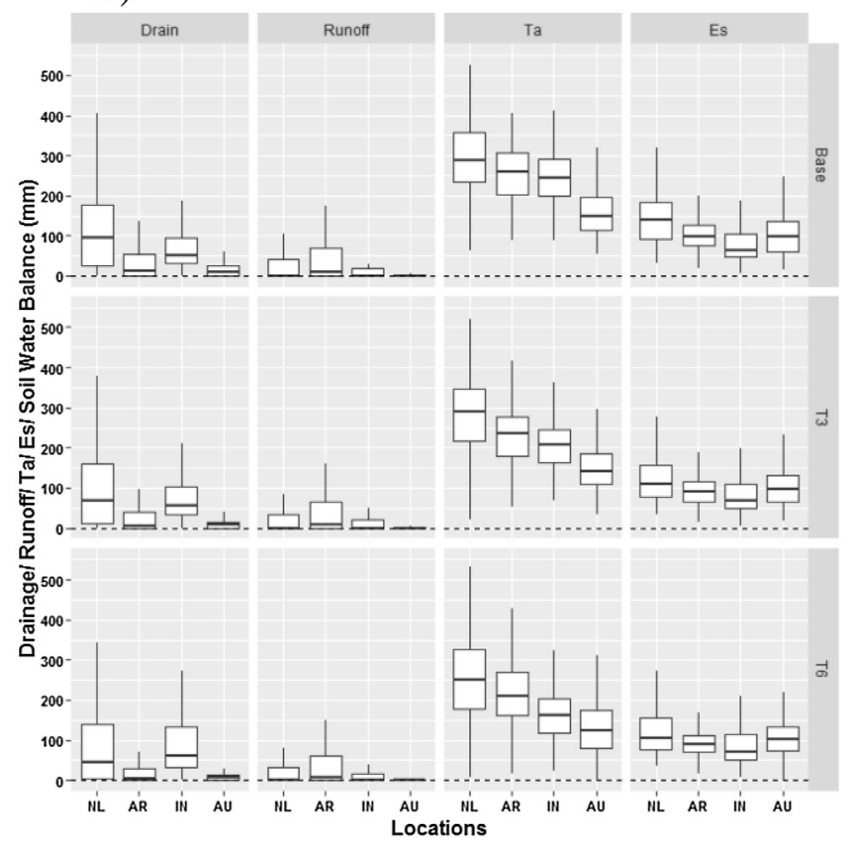

b)

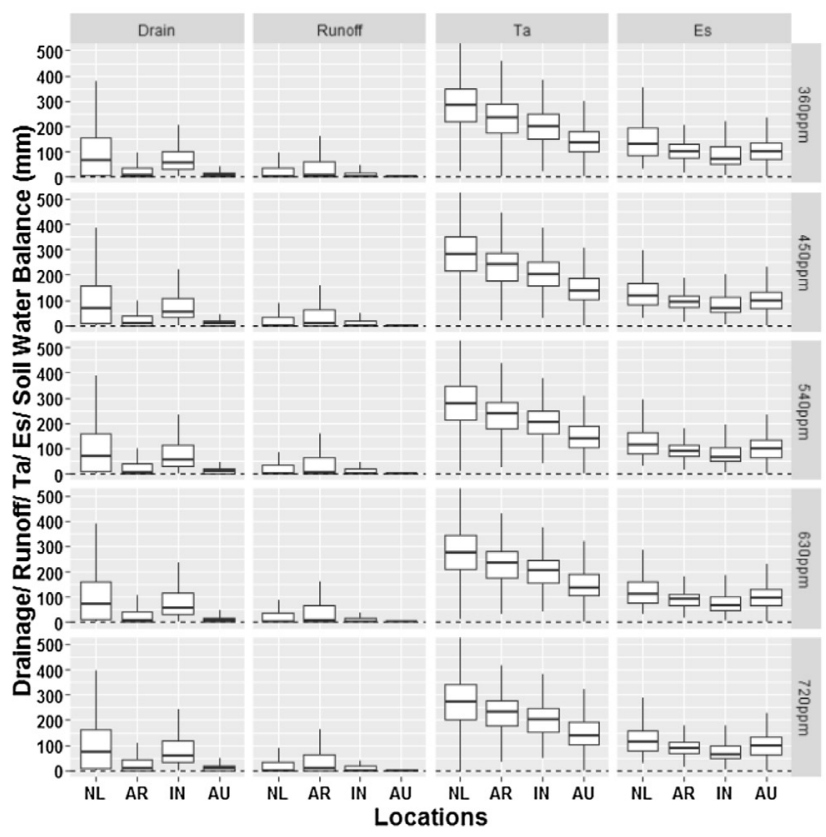

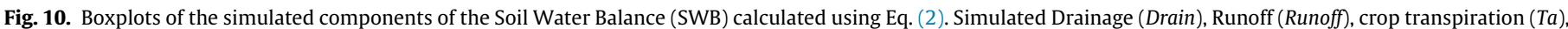

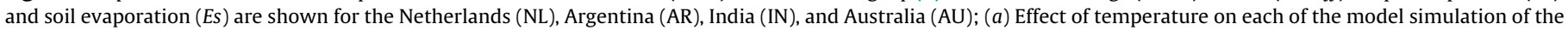
baseline 30-years period (Base), the increases in average daily air temperature of $3{ }^{\circ} \mathrm{C}(\mathrm{T} 3)$ and $6{ }^{\circ} \mathrm{C}(\mathrm{T} 6) ;(b)$ for the increases in atmospheric $\mathrm{CO}_{2}$ concentrations.

response to $\mathrm{CO}_{2}$ concentrations across different experiments (Long, 2012). A meta-analysis of wheat studies found that increasing $\left[\mathrm{CO}_{2}\right]$ from 400 to 800 ppm increases WUE by between 5 and $38 \%$ (Hatfield et al., 2011; Kimball et al., 2002; Long et al., 2006; Manderscheid and Weigel, 2007; Tao and Zhang, 2013; Wang et al., 2013). The results of this study regarding the simulated response at the four locations for WU, $Y$, and WUE to $\left[\mathrm{CO}_{2}\right]$ was in line with these studies. This concordance contrasts with claims that on average models overestimate $\left[\mathrm{CO}_{2}\right]$ effects (Ewert et al., 2007; Long et al., 2006; Tubiello et al., 2007).

Another important outcome of our study is to have traced the average pattern of WU, WUE, and $\mathrm{T}_{\text {eff }}$ change with temperature and $\left[\mathrm{CO}_{2}\right]$ increases. Despite variability, the majority of models had the same direction of change in $Y$, WU, WUE, and $T_{\text {eff }}$ in the sensitivity to temperature and $\left[\mathrm{CO}_{2}\right]$. This allowed us to draw conclusions about general crop responses when temperature and $\left[\mathrm{CO}_{2}\right]$ both change. 
The interaction between increase in temperature and increase in $\left[\mathrm{CO}_{2}\right]$ showed that, depending on the location, $Y$, WUE, and $T_{\text {eff }}$ reductions due to temperature can be largely offset by increasing $\left[\mathrm{CO}_{2}\right]$. The response of WUE to temperature is of particular interest since this response may be driving yield changes in many regions with limited rainfall and water for irrigation (Pirttioja et al., 2015).

The changes in temperature used in this study $\left(+3^{\circ} \mathrm{C}\right.$ and $\left.+6^{\circ} \mathrm{C}\right)$ caused more model output variability than the changes in atmospheric $\left[\mathrm{CO}_{2}\right]$ (from $360 \mathrm{ppm}$ to $720 \mathrm{ppm}$ at $90 \mathrm{ppm}$ intervals). But, the crop models' agreement related to the magnitude of changes is variable-specific. For example, crop models showed good agreement in terms of relative change of simulated $\mathrm{Y}$ under temperature and elevated $\left[\mathrm{CO}_{2}\right]$ changes, WU showed good agreement under temperature changes and lower agreement under $\left[\mathrm{CO}_{2}\right]$, while WUE, and $\mathrm{T}_{\text {eff }}$ showed less agreement under temperature changes and high agreement under elevated $\left[\mathrm{CO}_{2}\right]$ (Figs. 6 and 7).

\section{Conclusion}

The largest uncertainty in simulated crop WU among CSMs is due to differences in how models simulate crop transpiration. The simulated response to increased temperature caused a decline in WU. The sixteen models showed greatest uncertainty of simulated WUE, and $\mathrm{T}_{\text {eff }}$ at increased temperatures and with interactions between temperature and $\left[\mathrm{CO}_{2}\right]$. To improve the simulated impacts of climate change on crop water dynamics, crop transpiration in CSMs needs to be improved with detailed experimental data.

\section{Acknowledgments}

We thank the anonymous referees for the valuable comments and suggestions that helped improve the manuscript. S.G. was supported by a grant from the Ministry of Science, Research and Arts of Baden-Württemberg (AZ Zu 33-721.3-2) and the Helmholtz Center for Environmental Research, Leipzig (UFZ); R.P.R., T.P. and F.T. were supported by funds from the European FACCE MACSUR project through the Finnish Ministry of Agriculture and Forestry; P.M., P.B., N.B. and D.R. were supported by INRA Environment and Agronomy Division and by the funding within the framework of JPI FACCE MACSUR project through the INRA Metaprogram on the Adaptation of Agriculture and Forests to Climate Change; K.C.K. and C.N. received support from the German Federal Office for Agriculture and Food with FACCE MACSUR (2812ERA147) and from COST ES1106; C.M. acknowledges financial support from the KULUNDA project (01LL0905L) and the FACCE MACSUR project (031A103B) funded through the German Federal Ministry of Education and Research (BMBF); C.O.S. was supported by the project of Regional Approaches to Climate Change for Pacific Northwest Agriculture (REACCH-PNA) funded through award \#2011-68002-30191 from the National Institute for Food and Agriculture. This work has been carried out under the framework of the Agricultural Model Intercomparison and Improvment Project (AgMIP).

\section{Appendix A. Supplementary data}

Supplementary data associated with this article can be found, in the online version, at http://dx.doi.org/10.1016/j.fcr.2016.08.015.

\section{References}

Alcamo, J., Florke, M., Marker, M., 2007. Future long-term changes in global water resources driven by socio-economic and climatic changes. Hydrol. Sci J. 52 (2), 247-275.

Allen, R.G., Pereira, L.S., Raes, D., Smith, M., 1998. Crop Evapotranspiration: Guidelines for Computing Crop Water Requirements - FAO Irrigation and Drainage. FAO, via Terme di Caracalla, Rome, paper 56.
Angulo, C., et al., 2013. Implication of crop model calibration strategies for assessing regional impacts of climate change in Europe. Agric. Forest Meterol $170,32-46$.

Angus, J.F., van Herwaarden, A.F., 2001. Increasing water use and water use efficiency in dryland wheat. Agron. J. 93 (2), 290-298.

Asseng, S., et al., 1998. Performance of the APSIM-wheat model in western Australia. Field Crops Res. 57 (2), 163-179.

Asseng, S., et al., 2013. Uncertainty in simulating wheat yields under climate change. Nat. Clim. Change 3 (9), 827-832.

Bassu, S., et al., 2014. How do various maize crop models vary in their responses to climate change factors? Global Change Biol. 20 (7), 2301-2320.

Blum, A., 2005. Drought resistance, water-use efficiency, and yield potential - are they compatible, dissonant, or mutually exclusive? Aust. J. Agric. Res. 56 (11), 1159-1168.

Challinor, A.J., et al., 2014. A meta-analysis of crop yield under climate change and adaptation. Nat. Clim. Change 4 (4), 287-291.

Condon, A.G., Richards, R.A., Rebetzke, G.J., Farquhar, G.D., 2002. Improving intrinsic water-use efficiency and crop yield. Crop Sci. 42 (1), 122-131.

Condon, A., Richards, R., Rebetzke, G., Farquhar, G., 2004. Breeding for high water-use efficiency. J. Exp. Bot. 55 (407), 2447-2460.

Dixon, J., Braun, H.J., Crouch, J., 2009. Overview: transitioning wheat research to serve the future needs of the developing world. In: Dixon, J., Braun, H.J., Kosina, P., Crouch, J. (Eds.), Wheat Facts and Futures. CIMMYT, Mexico, D.F, p. 2009

Elliott, J., et al., 2014. Constraints and potentials of future irrigation water availability on agricultural production under climate change. Proc. Natl. Acad. Sci. U. S. A. 111 (9), 3239-3244.

Ewert, F., Porter, J.R., Rounsevell, M.D.A., 2007. Crop models, CO2, and climate change. Science 315 (5811), 459

Foley, J.A., et al., 2011. Solutions for a cultivated planet. Nature 478, 337-342.

French, R.J., Schultz, J.E., 1984. Water use efficiency of wheat in a Mediterranean-type environment. I the relationship between yield, water use and climate. Aust. J. Agric. Res. 35, 743-764.

Godfray, H.C.J., et al., 2010. Food security: the challenge of feeding 9 billion people. Science 327 (5967), 812-818.

Groot, J.J.R., De Willigen, P., Verberne, E.L.J., 1991. Nitrogen turnover in the soil-crop system. Developments in Plant and Soil Sciences, 44. Kluver Academic Publisher

Hatfield, J.L., et al., 2011. Climate impacts on agriculture: implications for crop production. Agron. J. 103 (2), 351-370.

Howell, T.A., 2001. Enhancing water use efficiency in irrigated agriculture. Agron. J. 93 (2), 281-289

Kersebaum, K.C., Nendel, C., 2014. Site-specific impacts of climate change on wheat production across regions of Germany using different $\mathrm{CO} 2$ response functions. Eur. J. Agron. 52, 22-32.

Kimball, B.A., Kobayashi, K., Bindi, M., 2002. Responses of agricultural crops to free-air CO2 enrichment. Adv. Agron. 77, 293-368.

Kingston, D.G., Todd, M.C., Taylor, R.G., Thompson, J.R., Arnell, N.W., 2009 Uncertainty in the estimation of potential evapotranspiration under climate change. Geophys. Res. Lett. 36.

Knox, J., Hess, T., Daccache, A., Wheeler, T., 2012. Climate change impacts on crop productivity in Africa and South Asia. Environ. Res. Lett. 7 (3).

Kool, D., et al., 2014. A review of approaches for evapotranspiration partitioning. Agric. Forest Meteorol. 184, 56-70.

Li, T., et al., 2015. Uncertainties in predicting rice yield by current crop models under a wide range of climatic conditions. Global Change Biol. 21 (3), 1328-1341

Long, S.P., Ainsworth, E.A., Leakey, A.D.B., Nosberger, J., Ort, D.R., 2006. Food for thought: lower-than-expected crop yield stimulation with rising CO2 concentrations. Science 312 (5782), 1918-1921.

Long, S.P., 2012. Virtual Special Issue on food security - greater than anticipated impacts of near-term global atmospheric change on rice and wheat. Global Change Biol. 18 (5), 1489-1490.

Müller, C., Robertson, R.D., 2014. Projecting future crop productivity for global economic modeling. Agric. Econ. 45 (1), 37-50.

Manderscheid, R., Weigel, H.J., 2007. Drought stress effects on wheat are mitigated by atmospheric CO2 enrichment. Agron. Sustain. Dev. 27 (2), 79-87.

Martre, P., et al., 2015. Multimodel ensembles of wheat growth: many models are better than one. Global Change Biol. 21 (2), 911-925.

McAfee, S.A., 2013. Methodological differences in projected potential evapotranspiration. Clim. Change 120 (4), 915-930.

McKenney, M.S., Rosenberg, N.J., 1993. Sensitivity of some potential evapotranspiration estimation methods to climate change. Agric. Forest Meteorol. 64 (1-2), 81-110.

Mearns, L.O., Rosenzweig, C., Goldberg, R., 1997. Mean and variance change in climate scenarios: methods, agricultural applications, and measures of uncertainty. Clim. Change 35 (4), 367-396.

Monfreda, C., Ramankutty, N., Foley, J.A., 2008. Farming the planet: 2. Geographic distribution of crop areas, yields, physiological types, and net primary production in the year 2000. Global Biogeochem. Cycles 22 (1).

Naveen, N., 1986. Evaluation of Soil Water Status, Plant Growth and Canopy Environemtn in Relation to Variable Water Supply to Wheat. Indian Agricultural Research Institute, New Delhi, India.

Osborne, T., Rose, G., Wheeler, T., 2013. Variation in the global-scale impacts of climate change on crop productivity due to climate model uncertainty and adaptation. Agric. Forest Meteorol. 170, 183-194. 
Passioura, J.B., Angus, J.F., 2010. Improving productivity of crops in water-limited environments. Adv. Agron. 106, 37-75.

Passioura, J., 2006. Increasing crop productivity when water is scarce - from breeding to field management. Agric. Water Manage. 80 (1-3), 176-196.

Penman, H.L., 1948. Natural evaporation from open water, bare soil and grass. Proc. R. Soc. Lond. Ser. A 193 (1032), 120.

Pirttioja, N., Carter, T.R., Fronzek, S., 2015. A crop model ensemble analysis of temperature and precipitation effects on wheat yield across a European transect using impact response surfaces. Climate Res. 65, 87-105.

Priestley, C., Taylor, R.J., 1972. On the assessment of surface heat flux and evaporation using large scale parameters. Mon. Weather Rev. 100 (2), 10.

Rötter, R., Van de Geijn, S.C., 1999. Climate change effects on plant growth, crop yield and livestock. Clim. Change 43 (4), 651-681.

Rötter, R.P., Carter, T.R., Olesen, J.E., Porter, J.R., 2011. Crop-climate models need an overhaul. Nat. Clim. Change 1 (4), 175-177.

Rötter, R.P., et al., 2012. Simulation of spring barley yield in different climatic zones of Northern and Central Europe: a comparison of nine crop models. Field Crop Res. 133, 23-36.

Reynolds, M., Braun, H., 2013. Achieving yield gains in wheat: overview. In: Reynolds, M., Braun, H. (Eds.), Proceedings of the 3rd International Workshop of the Wheat Yield Consortium. CIMMYT, Obregón, Sonora, Mexico.

Rienecker, M.M., et al., 2011. MERRA: NASA's modern-Era retrospective analysis for research and applications. J. Climate 24 (14), 3624-3648.

Rosenzweig, C., Parry, M.L., 1994. Potential impact of climate-change on world food-supply. Nature 367 (6459), 133-138.

Rosenzweig, C., Jones, J.W., Hatfield, J., Antle, J., 2011. AgMIP Protocols (accessed July 2014) http://www.agmip.org/agmip-protocols/.

Sadras, V.O., Angus, J.F., 2006. Benchmarking water-use efficiency of rainfed wheat in dry environments. Aust. J. Agric. Res. 57 (8), 847-856.

Semenov, M.A., Stratonovitch, P., Alghabari, F., Gooding, M.J., 2014. Adapting wheat in Europe for climate change. J. Cereal Sci. 59 (3), 245-256.

Shen, Y.J., Ok, T., Utsumi, N., Kanae, S., Hanasaki, N., 2008. Projection of future world water resources under SRES scenarios: water withdrawal. Hydrol. Sci. J. 53 (1), 11-33.

Siebert, S., Doll, P., 2010. Quantifying blue and green virtual water contents in global crop production as well as potential production losses without irrigation. J. Hydrol. 384 (3-4), 198-217.

Sinclair, T.R., Muchow, R.C., 2001. System analysis of plant traits to increase grain yield on limited water supplies. Agron. J. 93 (2), 263-270.
Tao, F.L., Zhang, Z., 2013. Climate change, wheat productivity and water use in the North China Plain: a new super-ensemble-based probabilistic projection. Agric. Forest Meteorol. 170, 146-165.

Tebaldi, C., Knutti, R., 2007. The use of the multi-model ensemble in probabilistic climate projections. Philos. Trans. R. Soc. A 365 (1857), 2053-2075.

Tilman, D., Balzer, C., Hill, J., Befort, B.L., 2011. Global food demand and the sustainable intensification of agriculture. Proc. Natl. Acad. Sci. U. S. A. 108 (50) 20260-20264.

Travasso, M.I., Magrin, G.O., Rodriguez, R., Grondona, M.O., 1995. Comparing CERES-wheat and SUCROS2 in the argentinean cereal region. In: Zerger, A. Argent, R.M. (Eds.), Internationa Congress on Modelling and Simulation. Modelling and Simulation Society of Australia and New Zealand. The University of Newcastle, Newcastle, NSW, pp. 366-369.

Tubiello, F.N., Ewert, F., 2002. Simulating the effects of elevated CO2 on crops: approaches and applications for climate change. Eur. J. Agron. 18 (1-2), 57-74.

Tubiello, F.N., et al., 2007. Crop response to elevated CO2 and world food supply - a comment on Food for Thought. . . by Long et al., Science 312: 1918-1921, 2006 Eur. J. Agron. 26 (3), 215-223.

Utset, A., Farre, I., Martinez-Cob, A., Cavero, J., 2004. Comparing Penman-Monteith and Priestley-Taylor approaches as reference-evapotranspiration inputs for modeling maize water-use under Mediterranean conditions. Agric. Water Manage. 66 (3), 205-219.

Wang, L., Feng, Z.Z., Schjoerring, J.K., 2013. Effects of elevated atmospheric CO2 on physiology and yield of wheat (Triticum aestivum L.): a meta-analytic test of current hypotheses. Agric. Ecosyst. Environ. 178, 57-63.

White, J.W., Hoogenboom, G., Kimball, B.A., Wall, G.W., 2011a. Methodologies for simulating impacts of climate change on crop production. Field Crop Res. 124 (3), 357-368

White, J.W., Hoogenboom, G., Wilkens, P.W., Stackhouse, P.W., Hoel, J.M., 2011b. Evaluation of satellite-based, modeled-derived daily solar radiation data for the continental United States. Agron. J. 103 (4), 1242-1251.

Wu, L., Kersebaum, K.C., 2008. Modeling water and nitrogen interaction responses and their consequences in crop models. In: Ahuja, L.R., Reddy, V.R., Saseendran, S.A., Yu, Q. (Eds.), Response of Crops to Limited Water: Understanding and Modeling Water Stress Effects on Plant Growth Processes. Advances in Agricultural Systems Modeling. ASA, CSSA, SSSA, Madison, WI, USA, pp. 215-249.

Xu, C.Y., Singh, V.P., 2002. Cross comparison of empirical equations for calculating potential evapotranspiration with data from Switzerland. Water Resour. Manage. 16 (3), 197-219. 